\title{
Effect of initial water flooding on the performance of polymer flooding for heavy oil production
}

\author{
Clement Fabbri ${ }^{1, *}$, Romain de-Loubens ${ }^{1}$, Arne Skauge ${ }^{2}$, Gerald Hamon ${ }^{1}$, and Marcel Bourgeois ${ }^{1}$ \\ ${ }^{1}$ Total S.A., Avenue Larribau, 64000 Pau, France \\ ${ }^{2}$ University of Bergen/Centre for Integrated Petroleum Research, Allegaten 41, 5007 Bergen, Norway
}

Received: 10 October 2019 / Accepted: 29 January 2020

\begin{abstract}
In the domain of heavy to extra heavy oil production, viscous polymer may be injected after water injection (tertiary mode), or as an alternative (secondary mode) to improve the sweep efficiency and increase oil recovery. To prepare field implementation, nine polymer injection experiments in heavy oil have been performed at core scale, to assess key modelling parameters in both situations. Among this consistent set of experiments, two have been performed on reconstituted cylindrical sandpacks in field-like conditions, and seven on consolidated Bentheimer sandstone in laboratory conditions. All experiments target the same oil viscosity, between $2000 \mathrm{cP}$ and $7000 \mathrm{cP}$, and the viscosity of Partially Hydrolyzed Polyacrylamide solutions (HPAM 3630 ) ranges from $60 \mathrm{cP}$ to $80 \mathrm{cP}$. Water and polymer front propagation are studied using $\mathrm{X}$-ray and tracer measurements. The new experimental results presented here for water flood and polymer flood experiments are compared with experiments described in previous papers. The effects of geometry, viscosity ratio, injection sequence on recoveries, and history match parameters are investigated. Relative permeabilities of the water flood experiment are in line with previous experiments in linear geometry. Initial water floods led to recoveries of 15-30\% after one Pore Volume Injected (PVI), a variation influenced by boundary conditions, viscosity, and velocities. The secondary polymer flood in consolidated sandstone confirms less stable displacement than tertiary floods in same conditions. Comparison of secondary and tertiary polymer floods history matching parameters suggests two mechanisms. First, hysteresis effect during oil bank mobilization stabilizes the tertiary polymer front; secondly, the propagation of polymer at higher oil saturation leads to lower adsorption during secondary experiment, generating a lower Residual Resistance Factor (RRF), close to unity. Finally, this paper discusses the use of the relative permeabilities and polymer properties estimated using Darcy equation for field simulation, depending on water distribution at polymer injection start-up.
\end{abstract}

\author{
List of symbols and abbreviations \\ $P \quad$ Pressure (bar) \\ $T \quad$ Temperature $\left({ }^{\circ} \mathrm{C}\right)$ \\ $K_{\mathrm{w}, \mathrm{o}} \quad$ Permeability to water or oil phase $\left(\mathrm{m}^{2}\right)$ \\ $k_{\mathrm{rw}} \quad$ Water phase relative permeability \\ $k_{\text {ro }} \quad$ Oil phase relative permeability \\ $k_{\text {rw }} / k_{\text {ro }}$ Ratio of water to oil relative permeability \\ $\rho \quad$ Density $\left(\mathrm{kg} / \mathrm{m}^{3}\right)$ \\ $\mu \quad$ Viscosity (Pa s) \\ $\sigma \quad$ Surface tension $(\mathrm{N} / \mathrm{m})$ \\ u In situ, or interstitial velocitiy $(\mathrm{m} / \mathrm{s})$ \\ $v \quad$ Darcy velocity $(\mathrm{m} / \mathrm{s})$
}

\footnotetext{
* Corresponding author: clement.fabbri@total.com
}

$\begin{array}{ll}\varphi & \text { Porosity } \\ S_{\mathrm{w}} & \text { Water saturation } \\ S_{\mathrm{o}} & \text { Oil saturation } \\ \mathrm{RF} & \text { Recovery Factor, \% of oil in place } \\ \mu_{\mathrm{r}} & \text { Viscosity ratio } \\ N_{\mathrm{ca}} & \text { Capillary number } \\ \mathrm{PVI} & \text { Pore Volume Injected } \\ R_{\mathrm{e}} & \text { Reynolds number } \\ \mathrm{RRF} & \text { Residual Resistance Factor } \\ \mathrm{IPV} & \text { Inaccessible Pore Volume } \\ S_{\mathrm{wi}} & \text { Irreducible water saturation } \\ S_{\mathrm{or}} & \text { Residual oil saturation } \\ k_{\mathrm{rw} 2} & \text { Hysteretic water relative permeability } \\ S_{\mathrm{wrm}} & \text { Maximum residual water saturation } \\ S_{\mathrm{wh}} & \text { Maximum historical value of water saturation }\end{array}$


$S_{\text {wfmin }} \quad$ Average water saturation at the water breakthrough

$S_{\text {wfmax }}$ Average water saturation at the end of the water injection

\section{Introduction}

\subsection{Polymer injection in viscous oil - primary, secondary, and tertiary recovery}

In 1000-10 $000 \mathrm{cP}$ oil, injecting water to sustain reservoir pressure leads to low recovery factors and intensive water cycling (Gao, 2011). In Pelican Lake field, recovery factors between $7 \%$ and $10 \%$ of oil in place were reported and drastic water cut increase was observed a few months after water injection (Delamaide et al., 2013).

In order to increase the pressure gradient across the field and hence improve oil production, viscous polymer can be injected initially, either as the primary recovery mechanism; or secondary, when polymer is injected after initial production under natural depletion or tertiary, when polymer is injected after a water injection phase.

Delamaide has compared the efficiency of these three mechanisms in Pelican Lake (Delamaide, 2016). For the patterns selected, the primary recovery seemed to get the best results. Then the recovery factor seemed statistically better for secondary than tertiary. However, field data showed faster recovery in tertiary, which was interpreted by the author as the impact of better polymer solution injectivity after the water injection phase, due to desaturation of the oil around the well. In Schrader Bluff pilot, tertiary polymer injection led to conformance improvement (Ning et al., 2019) and reduced water cycling. Injectivity was also reported to be key to sustain production. These observations illustrate the importance of modelling polymer behaviour near well bore at high velocity range with low oil saturation (Skauge et al., 2016) and far from the well at low velocities with higher oil saturation, which is the focus of this paper.

\subsection{Multiphase flow modelling approaches}

Different theoretical approaches exist to predict the displacement of hydrocarbon by aqueous solutions in the porous media. The first one is to solve fluid flow equations at pore scale taking into account relevant physics, using simplified physical model of porous media, as in the percolation theory, or using realistic pore network built from images of real porous media, such as microcomputedtomography (Blunt, 2001; Oren et al., 1998; Xu et al., 1999). These simulations can be calibrated with experimental work on micromodels (Lenormand et al., 1983) but their extension to field scale simulation is computationally expensive. Another alternative, developed recently, relies on a thermodynamic approach (Hassaizadeh and Gray, 1990; Niessner et al., 2011), but may require new experimental set-ups to derive adequate parameters.

Lastly, the extension of Darcy flow to multiphase flow is the most widely used in the petroleum industry because of its simplicity and reliability within the domain of application. It was developed by Muskat (1937) and Buckley and Leverett (1942) and can be summarized by equation (1), $\boldsymbol{u}_{\mathrm{o}, \mathrm{w}}$, being the oil or water velocity; $k_{\mathrm{ro}, \mathrm{w}}$, either the relative permeability to oil $\left(k_{\mathrm{ro}}\right)$ or to water $\left(k_{\mathrm{rw}}\right) ; K$, the reference rock permeability; $\mu_{\mathrm{o}, \mathrm{w}}$, the viscosity of the oil or the water; $\operatorname{grad} P_{\mathrm{o}, \mathrm{w}}$, the pressure gradient between the inlet and the outlet of the rock volume for the oil or the water and $\boldsymbol{g}$ the gravity acceleration:

$$
\boldsymbol{u}_{\mathrm{o}, \mathrm{w}}=-\frac{K k_{\mathrm{ro}, \mathrm{rw}}}{\mu_{\mathrm{o}, \mathrm{w}}} \cdot\left(\operatorname{grad} P_{\mathrm{o}, \mathrm{w}}-\rho_{\mathrm{o}, \mathrm{w}} \cdot \boldsymbol{g}\right) .
$$

This description is valid when the two fluids are continuous and distributed homogeneously in the elementary volume. It also assumes laminar flow and no viscous coupling between phases (Kalaydjian, 1990). We discuss hereafter the validity of this model for the water and polymer floods considered in this paper.

\subsection{Validity of Darcy-type equation for viscous oil water flooding}

When the injected fluid is significantly more mobile than the displaced one, local front perturbations are propagated in fingering patterns, called instabilities in the context of Petrophysics. Multiple 2D experiments on micromodels have evidenced such fingering when the viscous forces dominate capillary force (Lenormand et al., 1988). Corescale experiments followed by X-ray have also shown unstable displacement in 3D porous media (Fabbri et al., 2013; Fransham and Jelen, 1987; Skauge et al., 2011).

This study focuses on the fluid flow in $2000-7000 \mathrm{cP}$ oil reservoirs, where the injected water or polymer solutions velocity typically ranges from $1 \mathrm{~cm} / \mathrm{d}$ to $10 \mathrm{~cm} / \mathrm{d}$ far from the wellbore. In these conditions, Reynolds number $\left(\mathrm{R}_{\mathrm{e}}\right)$ and Capillary number $\left(N_{\text {ca }}\right)$ range respectively from $10^{-8}$ to $10^{-5}$ and from $10^{-9}$ to $10^{-6}$, a domain where the flow is laminar and viscous forces are preponderant. For all water flood experiments considered, $\mu_{\mathrm{r}} \gg 10 . \mathrm{R}_{\mathrm{e}}, \mu_{\mathrm{r}}$, and $N_{\text {ca }}$ are defined by equations (2)-(4) where $l$ is the characteristic linear dimension of the flow, $\mu, \rho, u$ are respectively the viscosity, the density, the velocity of the injected fluid, except stated otherwise. $\sigma$ and $\theta$ are the interfacial tension and the wetting angle:

$$
\begin{gathered}
\mathrm{R}_{\mathrm{e}}=\frac{\rho l u}{\mu}, \\
\mu_{\mathrm{r}}=\frac{\mu_{\text {fluid in place }}}{\mu_{\text {injected fluid }}}, \\
N_{\text {ca }}=\frac{\mu u}{\sigma \cos \theta} .
\end{gathered}
$$

Criteria for viscous unstability development has been discussed extensively in the literature for water floods (Artus et al., 2004; Doorwar and Mohanty, 2017; Hagoort, 1974; Levitt et al., 2011; Riaz and Tchelepi, 2004, 2006) and tested for polymer injection (Bouquet et al., 2019). In the 
context of unstable floods, Riaz et al. (2007) have illustrated that numerical simulation failed to capture correctly the shape and development of viscous finger for $\mu_{\mathrm{r}}=155$ and $\mu_{\mathrm{r}}=303$. For $7000 \mathrm{cP}$ oil $\left(\mu_{\mathrm{r}} \approx 7500\right)$, Bondino et al. (2011) illustrated that the production and pressure could be matched with water-wet relative permeabilities whereas the fingering pattern corresponded rather to intermediate wet or oil wet behaviour. For 2000-7000 cP oil ( $\mu_{\mathrm{r}}$ between 2100 and 7500), de Loubens et al. (2018) have also shown that water dendritic structures could not be matched together with water breakthrough times using Darcy-type simulator, whereas both were correctly captured by a Pore Network Model (PNM) with intermediate to mixed-oil-wet relative permeabilities.

However, to the authors' knowledge, most of field production forecasts for viscous oil use Darcy-type models and PNM are difficult to extend to this scale. Hence in this work, we derive the relative permeabilities from (1) during water and polymer flooding, but the functions derived during water flooding should be considered with caution. In particular, the impact of boundary conditions, such as pressure gradient or injection rail geometry, well captured in micromodel experiments, could be a source of variability among 3D core floods presented in the literature and will be specifically studied in this paper.

\subsection{Influence of polymer flooding in the case of viscous oil}

Lab-scale experiments on cores (Asghari and Nakutnyy, 2008; Fabbri et al., 2013; Levitt et al., 2011; Skauge et al., 2012) or on micromodels (Buchgraber et al., 2011; Doorwar and Mohanty, 2011), have illustrated stable displacement of 1000-10 $000 \mathrm{cP}$ oil with polymer solutions. Consistently, several experimental studies reported recovery factors up to $70 \%$ after tertiary polymer floods in $400-6000 \mathrm{cP}$ oil, even when polymer solution viscosity was as low as $3 \mathrm{cP}$ (Levitt et al., 2011; Seright et al., 2018; Wang and Dong, 2009). Seright et al. (2018) pointed out those high recoveries with low polymer concentrations could be explained by more stable than expected polymer displacement. Indeed, with water relative permeability lower than 0.04 after water floods and high residual resistance factors, polymer mobility would be lower than expected if based on viscosity ratio only.

Under this stability condition, history matching of experimental results using conventional Darcy-type simulators has been performed by several authors (Fabbri et al., 2014; Wassmuth et al., 2009).

\subsection{Description of the polymer properties in situ}

Mobility reduction can be modelled using two parameters: $\mu_{p}(\mathrm{cP})$ the viscosity of the polymer solution in porous medium and Residual Resistance Factor (RRF), the RRF generated by polymer chains once adsorbed (Gogarty, 1967). It can be experimentally determined from (5) or estimated based on pore throats and polymer chains dimensions (Chauveteau, 1981). The fraction of water saturated porosity inaccessible to polymer chains due to small pore throat sizes or excluded volume after adsorption is the Inaccessible Pore Volume (IPV):

$$
\mathrm{RRF}=\frac{\Delta P_{\text {water before polymer flood }}}{\Delta P_{\text {water after polymer flood }}} .
$$

More complex models have been developed to match experimental observations such as dependency of Irreducible Oil Saturation $\left(S_{\text {or }}\right)$ on the polymer concentration and Capillary Number $\left(N_{\text {ca }}\right)$ (Chen et al., 2008, 2011; Huh and Pope, 2008; Pandey et al., 2008). However, the number of variables necessary to calibrate these models before implementing them in full field simulations is challenging. Other experimental studies have pointed out observations not predicted by Darcy-type models: the existence of an optimum concentration of polymer for oil viscosity (Levitt et al., 2011; Wang and Dong, 2009) or the retention due to complex adsorption or mechanical retention (D'Angelo et al., 2003; Grattoni et al., 2004; Pancharoen and Kovscek, 2010).

\subsection{Impact of wettability on water and polymer floods results}

The wettability of the porous media is a key parameter for water injection results, as shown on lower viscosity oil and Berea sandstone (Jadhunandan and Morrow, 1995). Consistently, for $1000 \mathrm{cP}$ oil, Seright et al. (2018) showed that water injection leads to higher recovery on an intermediate to water wet state core, compared to the ones performed on a strongly hydrophobic polyethylene core. In this core, water relative permeability was 10 times lower with crude oil than with refined oil, which could be due either to rock-fluid interaction or to the core saturation history.

The influence of the wettability on the polymer recovery in intermediate oil viscosities, from $100 \mathrm{cP}$ to $200 \mathrm{cP}$, was studied in 1-4 Darcy Bentheimer sandstone (JuarezMorejon et al., 2018). Secondary or tertiary polymer flood recovery was higher for intermediate wettabilities than for water wet cores, with mineral oil (Finavestan). Contrastingly, Doorwar and Mohanty (2014) reported that the recovery was lower and slower in oil wet cores compared to water wet cores. This apparent contradiction may be explained either by the difference in mineralogy or by different wettability restauration procedures.

\subsection{Comparison of secondary and tertiary ultimate polymer flood recoveries in viscous oil}

Because of low water flood recoveries in 1000-10 $000 \mathrm{cP}$ oil, laboratory and field experience suggest that the sooner polymer is injected, the faster the oil recovery. Aside from this, ultimate recovery may also depend on the injection sequence.

Core floods realized with 5000-6000 $\mathrm{cP}$ oil reported that the secondary polymer flood ultimate recovery was $18 \%$ lower than the tertiary polymer flood results in high permeable sandstone (Fabbri et al., 2014). Similarly, the work conducted by Doorwar and Mohanty (2014) evidenced higher tertiary recovery when flooding $200 \mathrm{cP}$ oil in Carbonate and Berea sandstone cores. Contrastingly, 
the work carried out by Juarez-Morejon et al. (2018) in 100-200 cP oil showed that secondary experiments yield to higher ultimate recovery compared to tertiary experiments. Additionally, the sensitivities to water flooding duration (between 1 and 6.5 pore volume of water injected) showed that the more mature the water flood, the lower the final recovery factor, ranging from $56 \%$ to $72 \%$ in intermediate wet conditions.

\subsection{Objectives of the experimental and simulation work}

For practical and economic reasons, polymer injection rarely starts at first oil: primary, secondary, and tertiary floods may be at play in different areas of the field. During the interpretation phase, running simulations with adequate polymer properties and relative permeabilities will enable to better understand the field response and the role of geological heterogeneities (Delamaide and Corlay, 1994). To capture a representative range of flow conditions, nine corefloods in restored wettability conditions were carried out by varying:

- Cores geometry and injection rails, investigating the influence of laboratory settings on flow properties.

- Oil viscosity and injection sequence, to express field variability.

These experiments were interpreted with the same simulator used for field scale applications, but its applicability was carefully discussed based on front stability observations.

\section{Description of experimental set-up}

\subsection{Presentation of the two sets of experiments}

To widen the range of parameters investigated, experiments have been realized using two different experimental set-ups: one for unconsolidated sandstone and one for consolidated sandstone, which enabled to test different core geometries. For the sake of consistency, secondary (S) and tertiary (T) experiments are named chronologically, and according to the main parameter investigated ( $v$ for viscosity, $b$ for boundary condition and $g$ for geometry).

Two experiments in "field" conditions $\left(T=50{ }^{\circ} \mathrm{C}\right.$ and $P=25$ bar), S0 and T1, were performed in cylindrical sand pack reconstituted with sand from cores sampled in the field. The oil was recombined. Cores were cylindrical (approximately $30 \mathrm{~cm}$ long and $5 \mathrm{~cm}$ diameter). Initial conditions are detailed in Table 1 . The objective was to quantify the recoveries obtained in secondary and tertiary mode when the experimental conditions are as close as possible to the field conditions and use it as a benchmark to validate results obtained in the second set of experiments.

Additionally, seven experiments T2v, T3b, T4b, T5g, T6g, T7g, and S8 were performed on outcrop consolidated sandstone in laboratory conditions $\left(T=25{ }^{\circ} \mathrm{C}\right.$ and $P=1$ bar). Oil was diluted from stock tank oil. This set investigated four parameters, as shown in Table 2 :
1. Viscosity: $\mathrm{T} 2 \mathrm{v}$ is performed with $7000 \mathrm{cP}$ oil.

2. Boundary conditions: $\mathrm{T} 2 \mathrm{v}$, T3b, and $\mathrm{T} 4 \mathrm{~b}$ groove geometry and injection direction varies as described in Figure 1. Additional details on the procedure can be found in Skauge et al. (2012).

3. Slab geometry: T6g is a quarter of five spot geometry. $\mathrm{T} 7 \mathrm{~g}$ slab length is $90 \mathrm{~cm}$, three times longer than other slabs. T5g is a cubic sandstone sample of $30 \times 30 \times 30 \mathrm{~cm}$.

4. Initial water flooding effect: experiment S8 is a secondary experiment with no initial water injection.

\subsection{Coreflooding procedures}

Procedures for corefloods S0 and T1 have already been presented in details (Fabbri et al., 2013). Hereafter, we focus on T5g and S8 which have not been presented previously and highlight the differences between experimental conditions.

1. The slabs were initially saturated with water, and water permeability measurements were performed at $100 \%$ water saturation.

2. Stock tank oil (degassed) was injected in the rock and left during at least two weeks at room temperature $\left(25^{\circ} \mathrm{C}\right)$. Duration of the maturation is a common procedure in the industry based on sensitivities performed on lighter oil (Jadhunandan and Morrow, 1995). The influence of aging time on the wettability state of the Bentheimer rock was not tested during this study.

3 . The oil was replaced by diluted $2000-7000 \mathrm{cP}$ oil. Irreducible water saturation $\left(S_{\mathrm{wi}}\right)$ of $10 \%$ was achieved in average, $S_{\mathrm{wi}}$ ranging from $7 \%$ to $13 \%$. Permeability at $S_{\text {wi }}$ was estimated at this step.

4. Polymer solution was injected at approximately $5 \mathrm{~cm} /$ day, the estimated fluid velocity far from the well. In situ fluid velocities are defined in (6), where $Q$ is the injection rate, $A$ is the core or slab cross section and $\varphi$ is the porosity:

$$
u=\frac{Q}{A \varphi} .
$$

For all experiments performed in linear geometry, velocities vary from $3 \mathrm{~cm} /$ day to $5 \mathrm{~cm} /$ day, as mentioned in Table 3 . For experiment T6g, due to the quarter of five spot geometry, the velocity varies across the slab and is locally higher as it is inversely proportional to the distance from inlet. Water flood carried out at the same injected rate, except for $T 1$, for which water injection rate was three times faster. For T5g and S8, no chase water was injected after polymer flooding to determine end point water relative permeability.

Slabs were covered with Epoxy resin, with two grooves fitted at the inlet and outlet of the slab, to obtain a homogeneous pressure gradient across the rock. Injection was done via millimetric grooves designed to distribute homogeneously the fluid on the inlet. For experiments T3b, T4b, $\mathrm{T} 5 \mathrm{~g}, \mathrm{~T} 7 \mathrm{~g}$, and $\mathrm{S} 8$, the injection was done from bottom to 


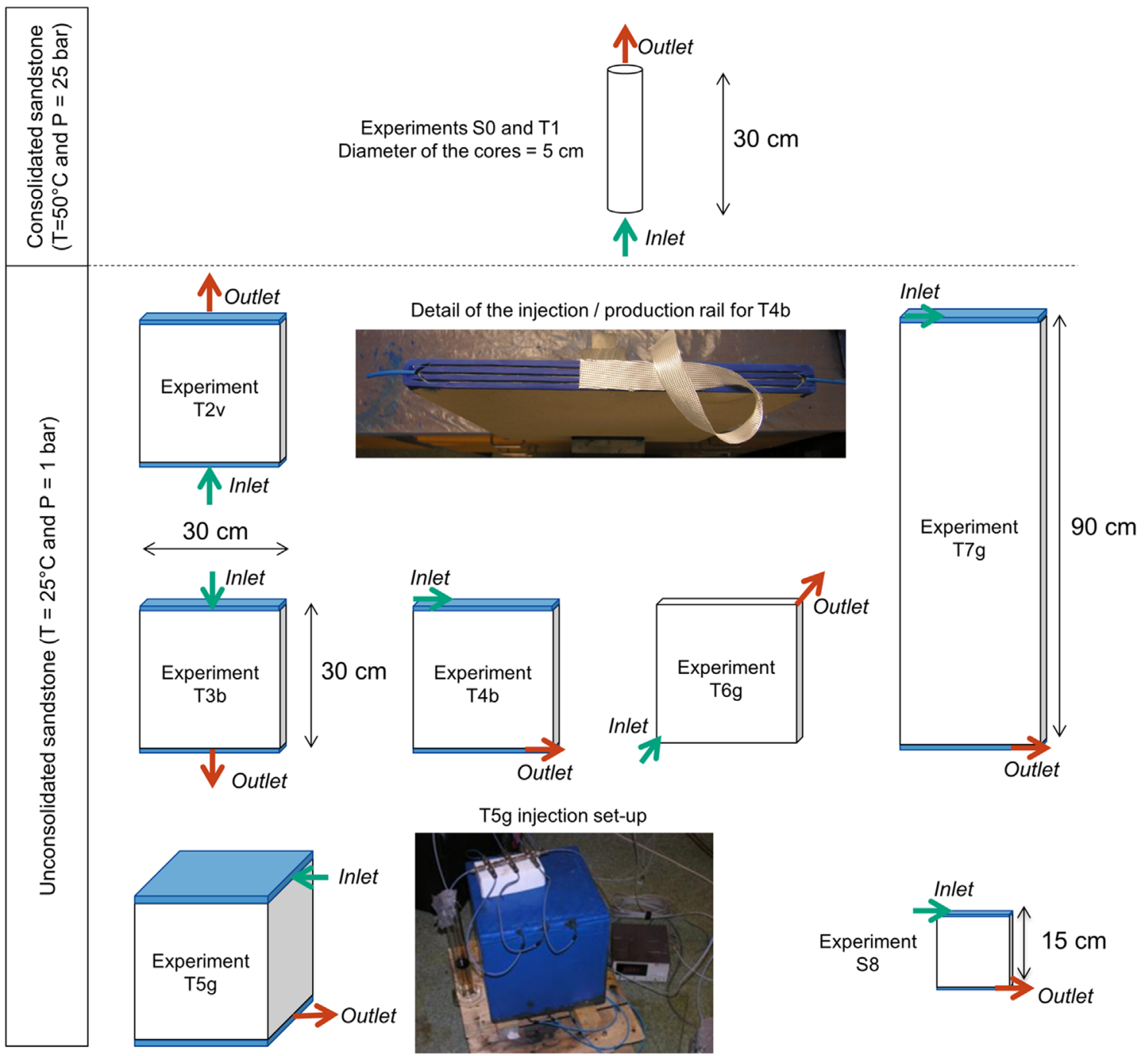

Fig. 1. Schematic drawing comparing the slabs geometries and injection and production rail orientations for experiments S0, T1, T2v, T3b, T4b, T5g, T6g, T7g, and S8.

top. Additional details on the set-up of experiments T3b, T4b, T6g, and T7g can be found in Fabbri et al. (2015).

T5g was performed on a $30 \times 30 \times 30 \mathrm{~cm}$ cube, whereas S8 was performed on a $15 \times 15 \times 2.1 \mathrm{~cm}$ slab. The injection rate was adjusted accordingly to maintain fluid velocity, as illustrated in Table 3. The injection grooves are different in 2D and in 3D slabs, as detailed in Figure 1. The pressure data acquired during the water flood step was noisy, which was believed to be an artefact due to the cubic geometry and the large volume of the injection and production rails.

\subsection{X-ray follow up}

For the first set of experiments, profiles were taken continuously along the core and on three diameters (central M0, $\mathrm{M} 1$, and M2 taken $-20^{\circ}$ and $+20^{\circ}$ around M0), with points every $5 \mathrm{~mm}$. A whole pass all along the core length on the three diameters lasted $4 \mathrm{~h}$. Due to averaging along the cross section of the cylindrical core, the saturation profile acquired in the first set up was not designed to capture lateral saturation variations.

In the second set of experiments, water flooding and polymer flooding were followed by X-ray with a NaI crystal scintillation photon counting detector, and an X-ray camera moving simultaneously with the $\mathrm{X}$-ray and low energy $\gamma$-ray source on each side of the rock sample, in vertical position. Figure 2 compares schematically the two X-ray acquisition set-up. Due to the thickness of the block, experiment T5g was not followed by X-ray.

X-ray pictures were acquired at high frequency initially (approximately every 0.01 Pore Volume Injected [PVI]) in order to capture the water breakthrough time. The scanning of each $30 \times 30 \times 2 \mathrm{~cm}$ slab lasted $5 \mathrm{~min}$ approximately. X-ray counting detector resolution was $5 \mathrm{~mm}$ by $5 \mathrm{~mm}$ whereas the X-ray camera captured slices of $0.5 \mathrm{~cm}$ by $11 \mathrm{~cm}$. Figure 3 compares the two types of acquisition obtained with the apparatus described. Additional details on measurement set-up, X-ray images and 


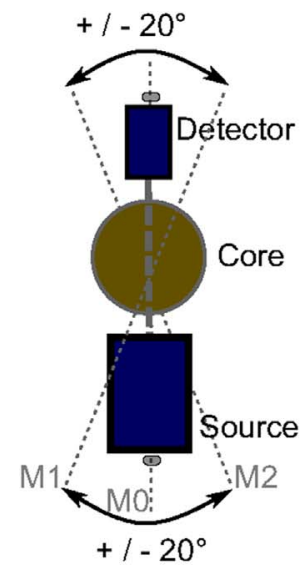

a)

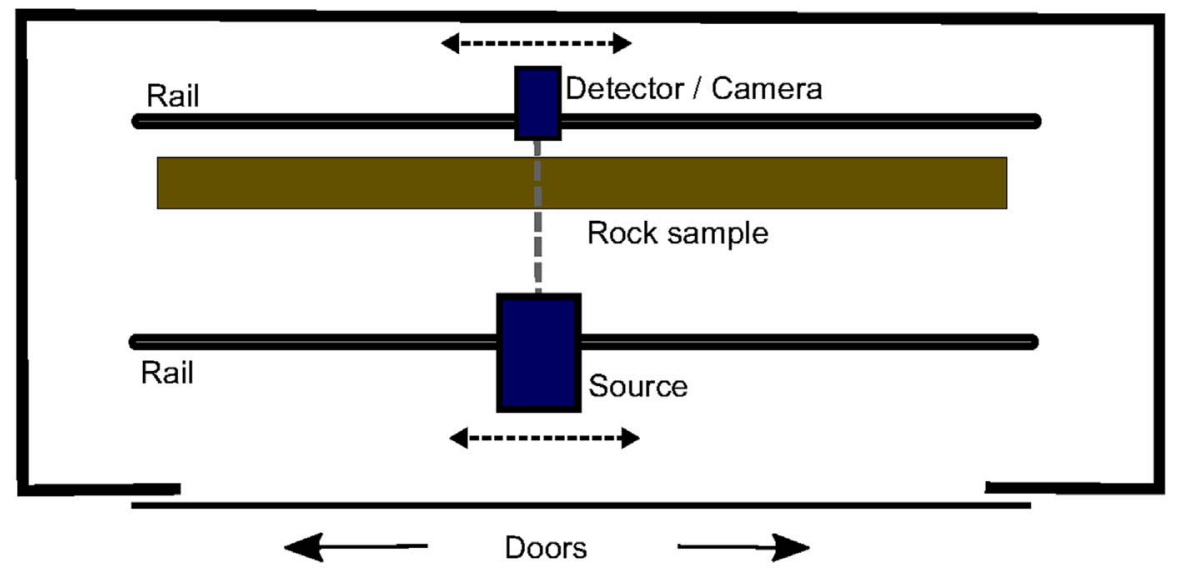

b)

Fig. 2. Cross-section schematics of X-ray scanning apparatus for experimental set (a) 1 and (b) 2, viewed from top of experiments.

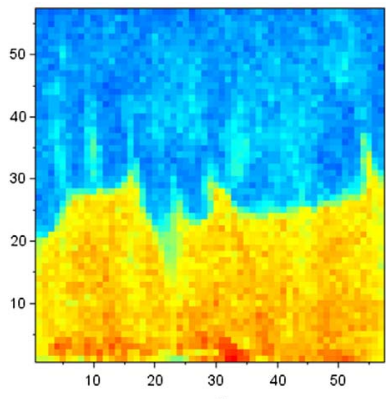

a)

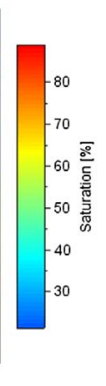

b)

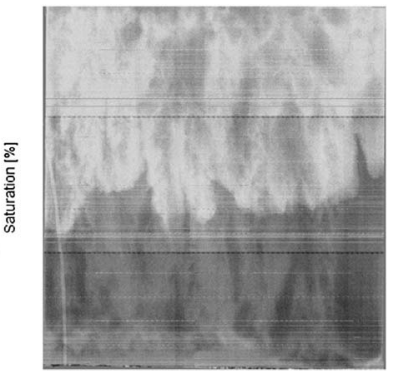

Fig. 3. Comparison of the two types of acquisitions for T4b at 0.48 PVI, after post-processing. (a) Oil saturation derived from $\mathrm{X}$-ray counting detector; $X$ and $Y$ axis represent the number of measurements in each direction. (b) X-ray image.

counting detection post-processing are detailed in Skauge et al. (2014) and Vik et al. (2018).

\subsection{Porous media}

The cylindrical cores prepared for the first set of experiments are reconstituted with sand sampled from cores of the reservoir of interest, in the hydrocarbon zone. Porosity was approximately $35 \%$, whereas permeability ranges from 4.5 to 8.2 Darcy, which was explained by the difference in the interval of the core sampled.

Contrastingly, all experiments from the second set have been performed on slabs cut from consolidated Bentheimer sandstone. Figure 4 presents the pore size distribution obtained from Bentheimer sandstone (Skauge et al., 2018) on a different experiment, but assumed to be representative of the slabs considered here. Peclet numbers estimated from tracer tests, between 150 and 300, also confirmed that the slabs were homogeneous and not dispersive (Fabbri et al., 2015).

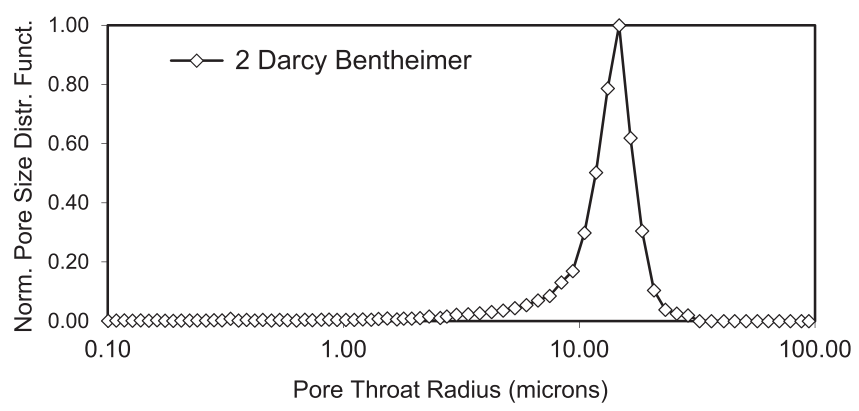

Fig. 4. Mercury injection derived pore throat distribution for Bentheimer core, reproduced from Skauge et al. (2018).

\subsection{Fluids}

\subsubsection{Water}

Compositions of the brines used for both set of experiment are detailed in Table 4. For X-ray resolution, water of the first set was doped by replacing the $2.1 \mathrm{~g} / \mathrm{L}$ of $\mathrm{NaCl}$ by $5 \mathrm{~g} / \mathrm{L}$ of $\mathrm{NaI}$, keeping an equivalent ionic force as the one of the reservoir water. In the second set of experiments, water was prepared with $6 \mathrm{~g} / \mathrm{L} \mathrm{NaCl}$ and $1 \mathrm{~g} / \mathrm{L} \mathrm{NaHCO}_{3}$. For T5g, the brine was prepared with $10 \% \mathrm{NaI}$ solution.

Water viscosity was $0.5 \mathrm{cP}$ in the first set of experiments, performed at $T=50{ }^{\circ} \mathrm{C}$ whereas it was $0.9 \mathrm{cP}$ in the second set of experiments, performed at $T=25^{\circ} \mathrm{C}$.

\subsubsection{Polymer}

Solutions of polymer were prepared with a high molecular weight partially hydrolyzed polyacrylamide (HPAM 3630).

For the first set of experiments, the polymer solution was saturated in $\mathrm{CO}_{2}$ in order to be in equilibrium with bicarbonate content of the water. Laboratory measurements confirmed that $\mathrm{CO}_{2}$ saturation did not modify the polymer viscosity. Quality control viscosity measurements 


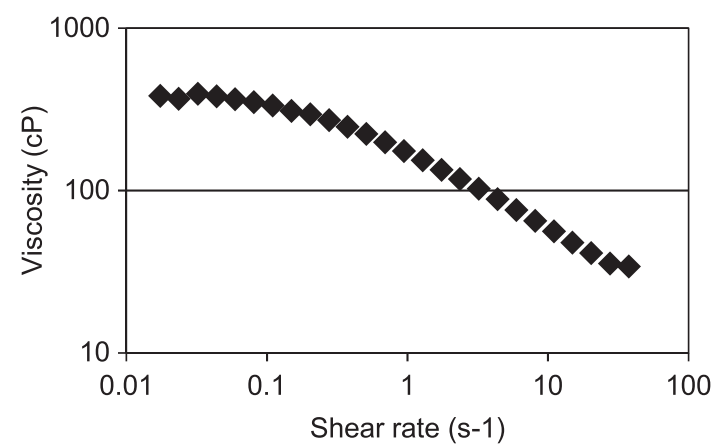

Fig. 5. Shear viscosity measured for HPAM 3630 with Anton Paar rheometer at $2000 \mathrm{ppm}$, at $T=25^{\circ} \mathrm{C}$.

were performed with a Low-shear Brookfield viscometer. After polymer solution preparation, solutions were filtered on polycarbonate filter $(5,2$, and $1 \mu \mathrm{m})$ under 1 bar Nitrogen overpressure. S0 was performed with a $2000 \mathrm{ppm}$ polymer solution of $67 \mathrm{cP}$ at $10 \mathrm{~s}^{-1}$, whereas due to change in the polymer batch, the same viscosity could not be reached, and a $2600 \mathrm{ppm}$ solution was prepared, with a viscosity of $80 \mathrm{cP}$ at $10 \mathrm{~s}^{-1}$ (Fabbri et al., 2014).

During the second set of experiments, the concentration was equal to $1650 \mathrm{ppm}$ for $\mathrm{T} 2 \mathrm{v}$, and to $2000 \mathrm{ppm}$ for T3b-S8. For these last experiments, polymer viscosity was estimated to be between $64 \mathrm{cP}$ and $76 \mathrm{cP}$ using Table 3 pore velocities and (7), where $v$ is the Darcy velocity, $k$ is permeability, $\varphi$ is porosity, and $C$ is a constant depending on the tortuosity, equal to 13 in this study:

$$
\dot{\gamma}=C \cdot\left(\frac{3 n+1}{4 n}\right) \cdot \frac{v}{\sqrt{k \cdot \varphi}}
$$

Shear thinning behaviour is shown on Figure 5. To simplify the history matching exercise, a Newtonian behaviour with constant viscosity of $70 \mathrm{cP}$ was assumed for all experiments performed in a linear geometry with 2000 ppm polymer solution.

The polymer solution was pre-filtered on a $40 \mu \mathrm{m}$ Swagelok filter, in order to remove the long polymerized chains that may generate an additional pressure effect at the inlet of the core. This prefiltration was not used for the second batch of polymer injected during T5g, which led to plugging at the inlet of the cubic rock sample.

\subsubsection{Oil}

The oil was obtained by diluting the dead oil with $18 \%$ 1-iododecane, to obtain an absorption contrast with the water phase, and $4 \%$ xylene. For T5g, the dead oil was mixed with $7 \%$ xylene only because it was not monitored by X-ray.

\subsubsection{Tracer solution}

During experiment S8, Lithium tracers have been used to follow polymer breakthrough. When injected in polymer solution, the concentration of $\mathrm{Li}$ used was $70-75 \mathrm{ppm}$ because polymer solutions were diluted before analyzing by Inductively Coupled Plasma Mass Spectrometry. Tracer injection were also performed at $100 \%$ water saturation for experiments $\mathrm{T} 2 \mathrm{v}, \mathrm{T} 3 \mathrm{~b}, \mathrm{~T} 4 \mathrm{~b}, \mathrm{~T} 5 \mathrm{~g}$, and $\mathrm{T} 7 \mathrm{~g}$ in order to ensure that the slabs were homogeneous and not too dispersive. More details regarding monophasic and diphasic tracer tests results can be found in previous work (Fabbri et al., 2013, 2015).

\section{Results and discussion}

\subsection{Comparison of the experimental results}

The oil recovery after water and polymer flooding are summarized in Table 5 and production and pressure are represented in Figure 6. Main observations are listed below:

1. T2v coreflood, with $7000 \mathrm{cP}$ oil exhibit a lower recovery after 1 Pore Volume (PV) of water and polymer, consistently with literature results (Wang and Dong, 2009). As shown by the production increase trend in Figure 6, this difference is due to slow mobilization of the oil, rather than a difference in $S_{\text {or }}$.

2. Although experiments T3b, T4b, T7g only differ by the injection groove and orientation of the flood, recoveries after 1 PVI range from $22 \%$ to $30 \%$. Additionally, Figure 6 illustrates that the variance of water flood recoveries increases with time, which highlights the influence of small perturbations during water flooding.

3. In $2000 \mathrm{cP}$ oil, ultimate recoveries after polymer flooding range from $67 \%$ to $75 \%$. One explanation for these variations is the uncertainty of oil recovery quantification for such viscous oil, as mentioned in Fabbri et al. (2013). Hence, the difference in cumulative oil produced between secondary and tertiary experiments should be considered with care. Similarly to what is concluded by Seright et al. (2018), the authors do no observe that trapped oil is mobilized at microscopic scale with secondary or tertiary polymer flooding, rather the final recovery at core scale is a function of the flood stability, as documented in Doorwar and Mohanty (2017).

4. Experiment T5g results do not differ significantly from the other water floods in $2000 \mathrm{cP}$ oil. This suggests that the same type of flow is expected on the slabs and in the cubic geometries when the flow is linear, as shown on Figure 1.

5. T6g pressure gradient is $3 \mathrm{bar} / \mathrm{m}$, approximately three times higher than other experiments in $2000 \mathrm{cP}$ oil, due to local plugging at the inlet of the core as explained in de Loubens et al. (2018). T2v initial higher pressure gradient is due to higher oil viscosity.

6. Experiments $\mathrm{T} 2 \mathrm{v}-\mathrm{S} 8$ are consistent with the experiments S0 and T1 realized in field like conditions, for production and pressure data, indicating that the wettability and fluid properties are also representative of field behavior during the second set of experiments. 


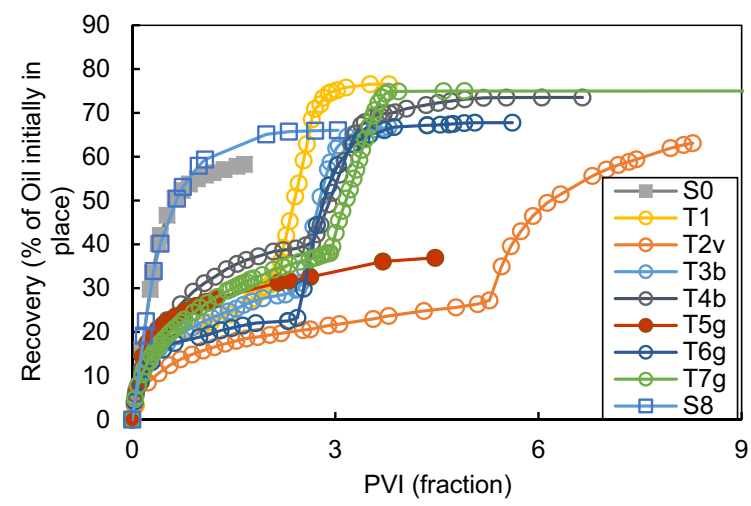

a)

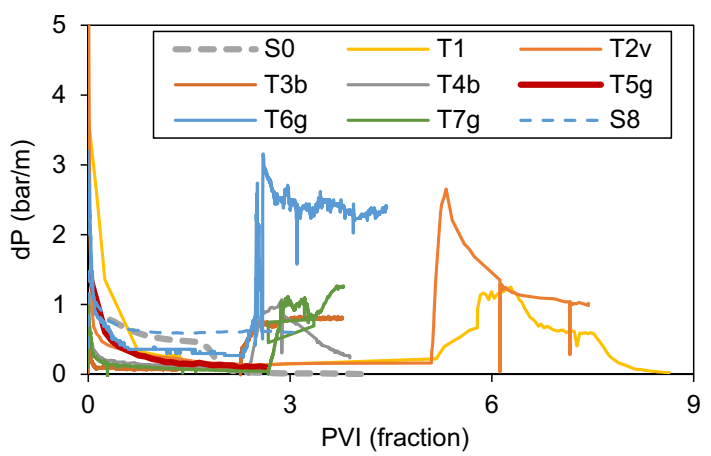

b)

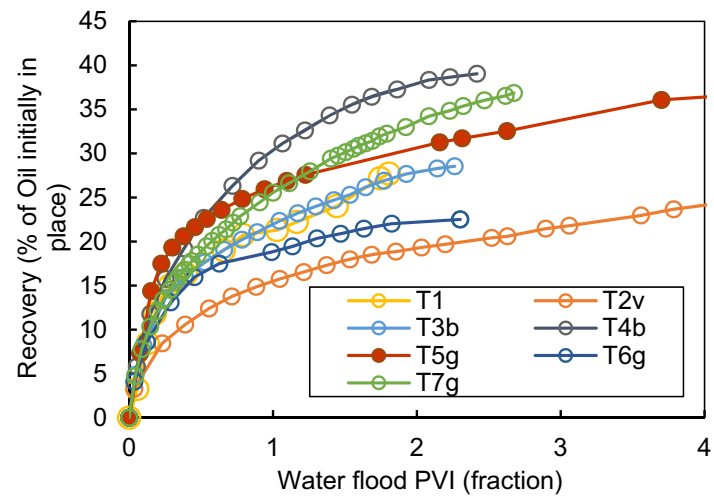

c)

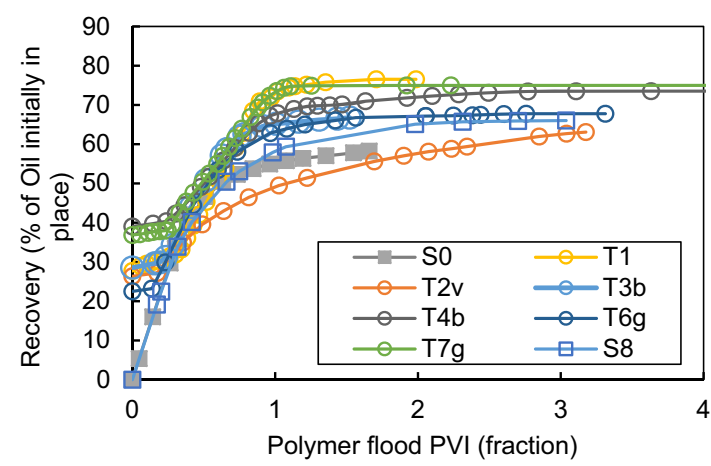

d)

Fig. 6. (a) Comparison of the cumulative oil recovery and (b) pressure gradient in bar/m in function of Pore Volume of Fluid Injected (PVI). (c) Zoom on water flood, and (d) polymer flood recoveries.

\subsection{Viscous fingering pattern observed during water flooding}

Figure 7 compares the viscous fingering pattern of water flood experiments at the water breakthrough time, at approximately 0.04 pore volume of water injected. Experiments T4b X-ray image is compared with images for experiments T2v, T3b, T6g, and T7g, already presented in the literature (de Loubens et al., 2018; Skauge et al., 2014). T2v is the only experiment carried with $7000 \mathrm{cP}$ oil. The viscous fingers evidenced here are comparable to the observations made on micromodels (Buchgraber et al., 2011; Lenormand et al., 1983) and on Bentheimer slabs (Skauge et al., 2009, 2011).

During the water flood of T1, X-ray measurements were averaged over the core thickness, as shown schematically in Figure 2, which did not enable to capture the fingering pattern but evidenced unstable front (Fabbri et al., 2014).

Figure 7 shows that T3b digitations are more central than in T4b, which could be explained by the central position of the feeding inlet of the injection rail in this specific experiment, as illustrated in Figure 1. Thinner fingers can be observed in the experiment $\mathrm{T} 2 \mathrm{v}$ and close to the slab outlet in T6g. This difference is consistent with Saffman Taylor findings, as their work evidenced decrease in finger width when the $N_{\text {ca }}$ increased (Saffman and Taylor, 1958). Paradoxically, given the recoveries variability and the different fingering patterns, for all experiments the water breakthrough occurs approximately at 0.04 pore volume of water injected. At core scale these observations evidence that the rock geometry and the injection rail play a significant role in the water fingers distribution and may explain variation in production shown on Figure 6. Since numerical simulations with Darcy simulators did not enable us to capture accurately these patterns (de Loubens et al., 2018), relative permeability sets obtained by history matching are expected to differ from one experience to another.

\subsection{Water flood history matching}

T5g water flood extends the results presented previously, with the same methodology (de Loubens et al., 2018; Fabbri et al., 2015): water flood relative permeability match was performed with our In-house Research Reservoir Simulator (IHRRS) (Patacchini et al., 2014) coupled with a curve optimization tool. The model used was a 1D uniform grid, with grid blocks of $1 \mathrm{~mm}$, to account for the low physical dispersion measured by tracer tests. Numerical scheme used is a fully implicit scheme with maximum time steps of 0.01 days. Similarly to the work done for experiments T3b, T4b, T7g (Fabbri et al., 2015) and T2v, T6g (de Loubens et al., 2018), capillary pressure effect was assumed to be negligible due to the high viscous pressure drop measured, the homogeneity of the core evidenced by dispersion tests and the limited end effect observed on saturation maps.

The fingering patterns observed in Figure 7 are also expected to be present in T5g because the injection geometry is linear and since pressure and production data are 


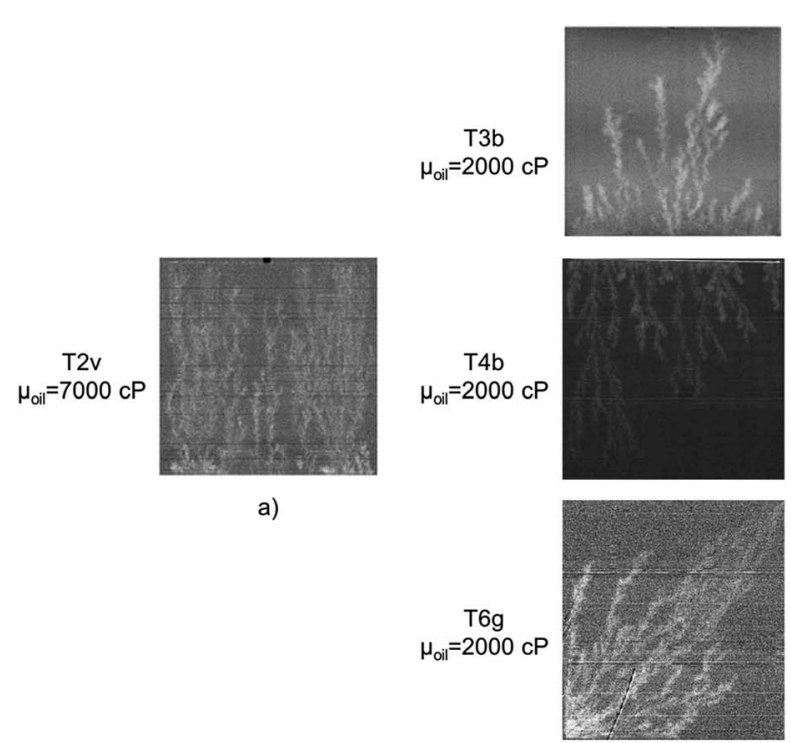

b)

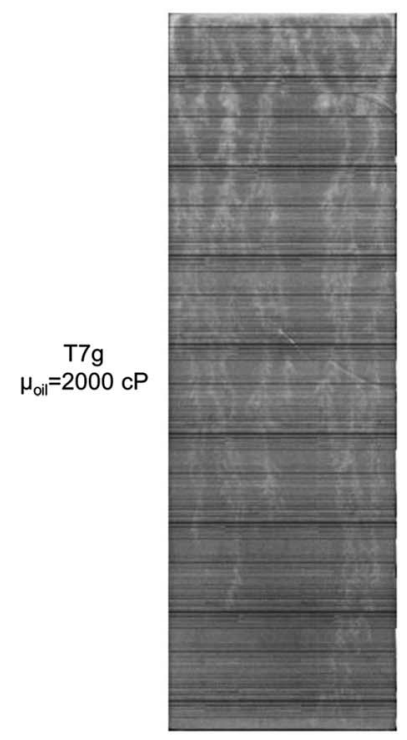

c)

Fig. 7. X-ray images captured during water flooding, approximately at the time of the water breakthrough, which occurs at 0.04 pore volume of water injected.

consistent with 2D slabs results, as shown in Figure 6 . However, as we were not able to predict accurately fingering patterns for the water floods using Darcy simulator (de Loubens et al., 2018), the history matching exercise of the water flood only aims at comparing qualitatively the mobility of the water phase by focusing on production and pressure data. Error bars on Figure 8 represent the variation of the signal, averaged for each $0.1 \mathrm{PVI}$, which is believed to be an artefact due to the injection/production rails of the cubic block $(30 \times 30 \times 30 \mathrm{~cm})$.

In Figure 9, experiment T5g water/oil relative permeabilities ratio is compared with the ones of the other experiments (de Loubens et al., 2018; Fabbri et al., 2015). Each set is plotted on the saturation range investigated at core scale during the water flood.

Three groups can be identified based on this parameter: T2v (linear geometry and $7000 \mathrm{cP}$ oil); T3b, T4b, T5g, T7g (linear geometry with $2000 \mathrm{cP}$ oil); and T6g (quarter of five spot geometry with $2000 \mathrm{cP}$ oil). This confirms that the water mobility is influenced by oil viscosity and core geometry in the context of unfavourable viscosity ratios. This grouping is believed to be an effect of viscosity and velocity on front stability as evidenced by Lenormand et al. (1983) with micromodels.

However, among linear geometry relative permeabilities group, Figure 9 also shows that variability increases at higher water saturations. End-point relative permeabilities were not investigated, by design, but a minimum of 1.8 pore volume of water was injected prior to tertiary polymer injection start-up.

\subsection{Comparison of front stability during secondary and tertiary polymer floods}

In both sets of experiments redundant data was acquired to understand variation in recoveries and support history matching. During S8, Li tracer was injected with the polymer solution in order to compare the water, tracer, and polymer breakthrough. Polymer concentration was followed indirectly by measuring viscosity of aqueous effluents.

X-ray images of polymer solutions invading $2 \mathrm{D}$ slabs are compared in Figure 10 for experiments T7g, T4b, and S8 at different PVI. For secondary polymer injection S8, breakthrough occurs at $0.23 \mathrm{PVI}$, whereas it occurs at later times, PVI $>0.5$, for tertiary experiments T4b and T7g. The fingering pattern is also more pronounced at $0.05 \mathrm{PVI}$ in S8 whereas the polymer front is more stable in $\mathrm{T} 4 \mathrm{~b}$ and $\mathrm{T} 7 \mathrm{~g}$. Consistently, the recovery is found higher for the tertiary experiments (65-73.5\% after water flood and 1 PVI of polymer) than for the secondary ones $(55.2 \%$ and $58.2 \%$ after 1 PVI of polymer).

These observations are in line with unconsolidated sandstone experiments, reminded in Figure 11, where the secondary saturation profile estimated from X-ray showed less stable displacement than tertiary. Similarly, polymer solution breakthrough was observed between 0.27 PVI and 0.3 PVI (Fabbri et al., 2014). Although variations in sandpack permeability, oil and polymer viscosity could explain the difference in front stability, shock viscosity ratios were found to be very similar (Fabbri et al., 2014) for unconsolidated experiments. Furthermore, permeability and viscosity variations were minimized between consolidated slabs, as shown in Table 1, suggesting that difference in front stability may be due to different polymer behavior in-situ.

\subsection{Secondary polymer flooding history matching}

We compare hereafter tertiary floods relative permeabilities and polymer properties, established in previous publications, with the history match of the secondary experiment S8. 

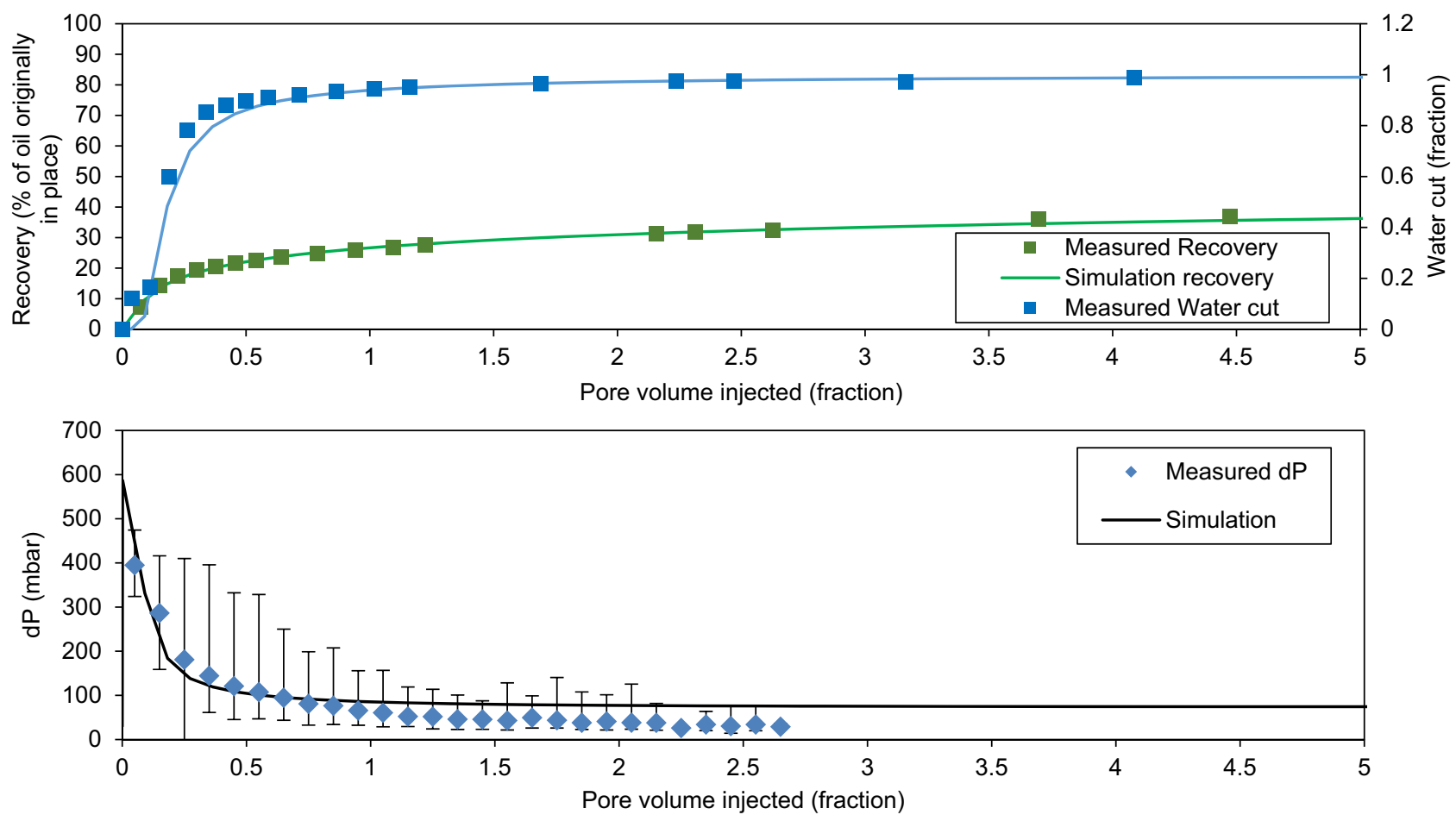

Fig. 8. Result of the water flood history match (oil production at the top and differential pressure at the bottom).

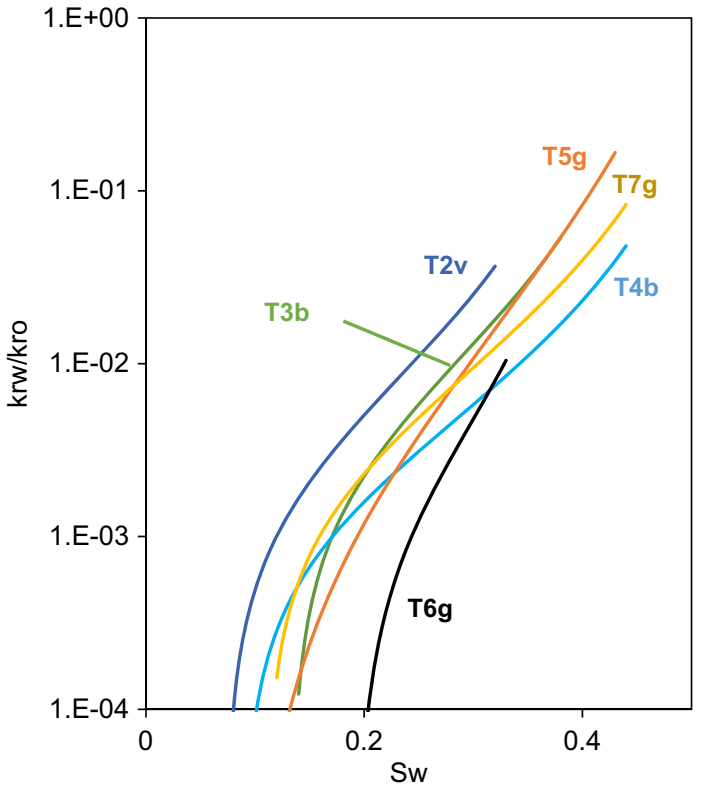

Fig. 9. Ratio $k_{\mathrm{rw}} / k_{\mathrm{ro}}$ for the water flood, on the averaged saturation domain where the $k_{\mathrm{rs}}$ are valid.

\subsubsection{Model used to history match tertiary polymer floods}

Previous work was focused on tertiary flood history matching with IHRRS simulator, in which polymer model follows equations detailed in Delshad et al. (2000). To focus on the stable polymer displacement and account for saturation

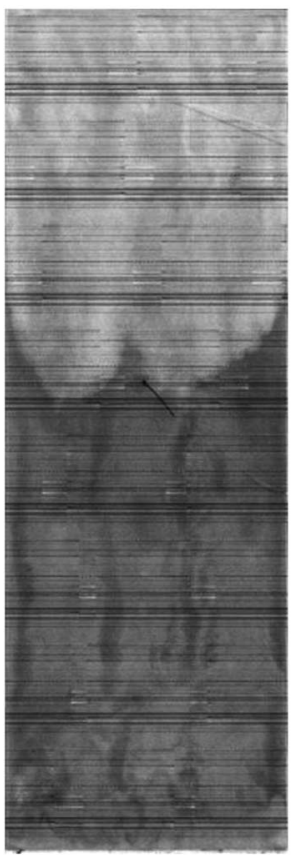

$0.23 \mathrm{PVI}$

a)

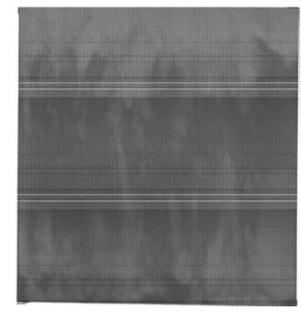

$0.16 \mathrm{PVI}$

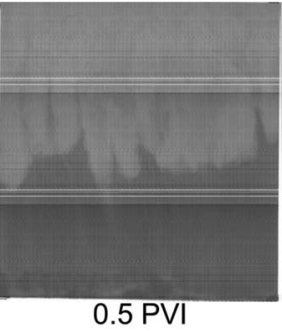

b)
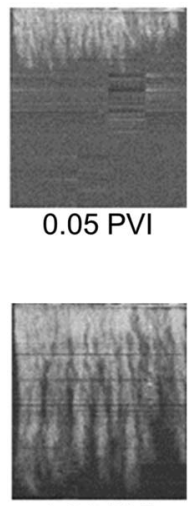

$0.23 \mathrm{PVI}$

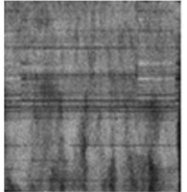

$1 \mathrm{PVI}$

c)
Fig. 10. Comparison of saturation front X-ray image during (a) secondary polymer flooding for $\mathrm{T} 7 \mathrm{~g}$, (b) T4b, and (c) tertiary polymer flooding for S8.

variations during water injection, simulations were initialized with saturation maps at the end of the water flood, estimated based on X-ray measurements. With these 


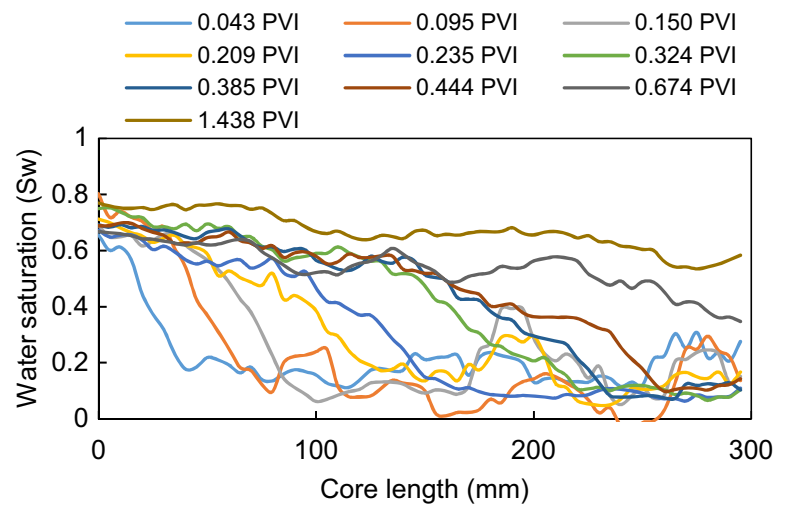

a)

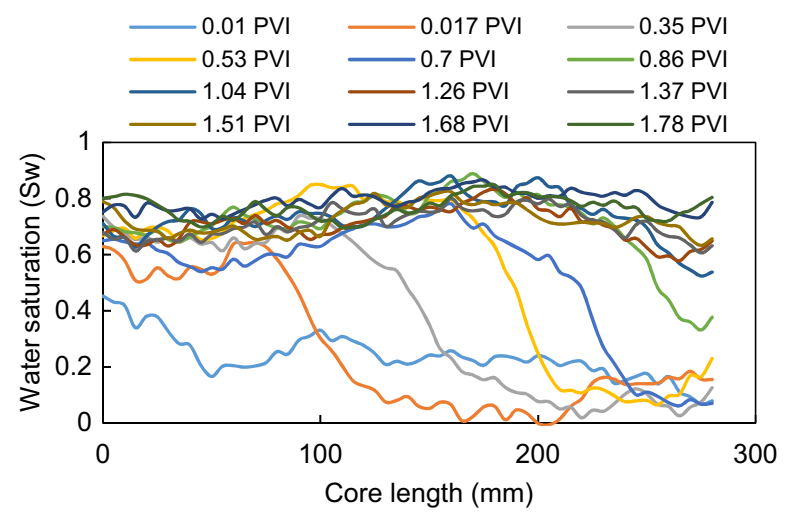

b)

Fig. 11. Comparison of the water saturation profiles obtained by X-ray during (a) the secondary S0 and (b) tertiary T1 polymer floods at different Pore Volume Injected (PVI).

Table 1. Summary of first set of experiments.

\begin{tabular}{|c|c|c|c|c|c|c|c|c|c|}
\hline \multirow[t]{2}{*}{ Exp } & \multirow[t]{2}{*}{ Geometry } & \multirow[t]{2}{*}{$\begin{array}{l}\text { Size } \\
(\mathrm{cm})\end{array}$} & \multirow[t]{2}{*}{$\begin{array}{l}\text { Porosity } \\
\text { (fraction) }\end{array}$} & \multicolumn{2}{|c|}{ Permeability (Darcy) } & \multirow{2}{*}{$\begin{array}{c}\text { Initial water } \\
\text { saturation } \\
\text { (fraction) }\end{array}$} & \multirow{2}{*}{$\begin{array}{c}\text { Oil } \\
\text { viscosity } \\
(\mathrm{cP})\end{array}$} & \multicolumn{2}{|c|}{$\begin{array}{l}\text { Viscosity } \\
\text { ratio }\left(\mu_{\mathrm{r}}\right)\end{array}$} \\
\hline & & & & $\begin{array}{c}K_{\mathrm{w}} \\
\left(S_{\mathrm{w}}=1\right)\end{array}$ & $\begin{array}{c}K_{o}\left(S_{\mathrm{wi}}\right) \\
\text { after aging }\end{array}$ & & & $\begin{array}{l}\text { Water } \\
\text { flood }\end{array}$ & $\begin{array}{c}\text { Polymer } \\
\text { flood }\end{array}$ \\
\hline S0 & Cylindrical & $L=30, \varphi=5$ & 0.35 & 8.2 & 7.8 & 0.11 & 5400 & 10000 & 81 \\
\hline T1 & Cylindrical & $L=29, \varphi=5$ & 0.34 & 4.5 & 3.7 & 0.07 & 5700 & 10556 & 70 \\
\hline
\end{tabular}

assumptions, history matching of experiments T3b, T4b, and $77 \mathrm{~g}$ could only be done when modelling hysteresis between the imbibition in non-water flooded area and the drainage during mobilization of oil bank in water fingers (Fabbri et al., 2015). Although a decent match could be obtained for each experiment independently, it was not possible to reconcile the match of cores of different lengths nor to capture the oil bank velocity unless the hysteresis was modelled. This finding was then extended to experiments T6g, in a quarter of five spot geometry (de Loubens et al., 2018).

Figure 12 represents a schematic view of the hysteresis model developed in Fabbri et al. (2015). In this context, porous media are assumed to be preferentially oil-wet, hence in our model only the water relative permeability is changed during the oil-bank movement, which may be a simplification with regards to results in intermediate oilwet media evidencing both water and oil relative permeability hysteresis (van der Post et al., 2000). Physically, it means that the oil mobilized by the polymer solution preferably flows in zones with high oil saturation and tends to trap water behind.

$K_{\text {rw }}$ and $K_{\text {ro }}$ are extrapolated with simple power-law in the domain where they are not determined during the water flood, i.e. between $S_{\text {wfmax }}$, the average water saturation at the end of the water flood and $1-S_{\mathrm{or}}$. As discussed in de Loubens et al. (2018), we believe that in this specific context this simple approach can be used because the saturation domains for water and polymer injection are almost

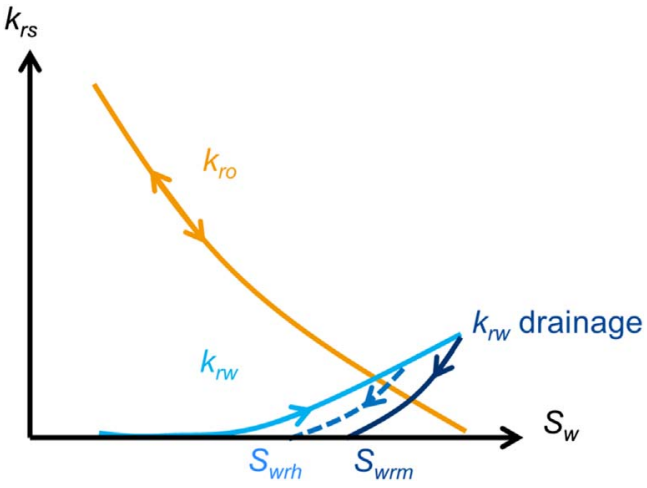

Fig. 12. Schematic view of the hysteresis model.

disjoint. However when water and polymer injection cover same saturation interval, as expected for lower viscosity ratio, two relative permeability sets may be defined, or alternatively a model where relative permeability is modified based on flow characteristics, as proposed in Luo et al. (2016).

Secondary drainage water relative permeability is denoted by $K_{\mathrm{rw} 2}$. The maximum saturation endpoint of this curve is given by $S_{\mathrm{w}}=1-S_{\mathrm{or}}$ and its lower endpoint is $S_{\mathrm{w}}=S_{\mathrm{wrm}}$, corresponding to the maximum residual (trapped) water saturation. In Killough's model the scanning curve emanating from the maximum historical value $S_{\mathrm{wh}}$ is calculated according to: 

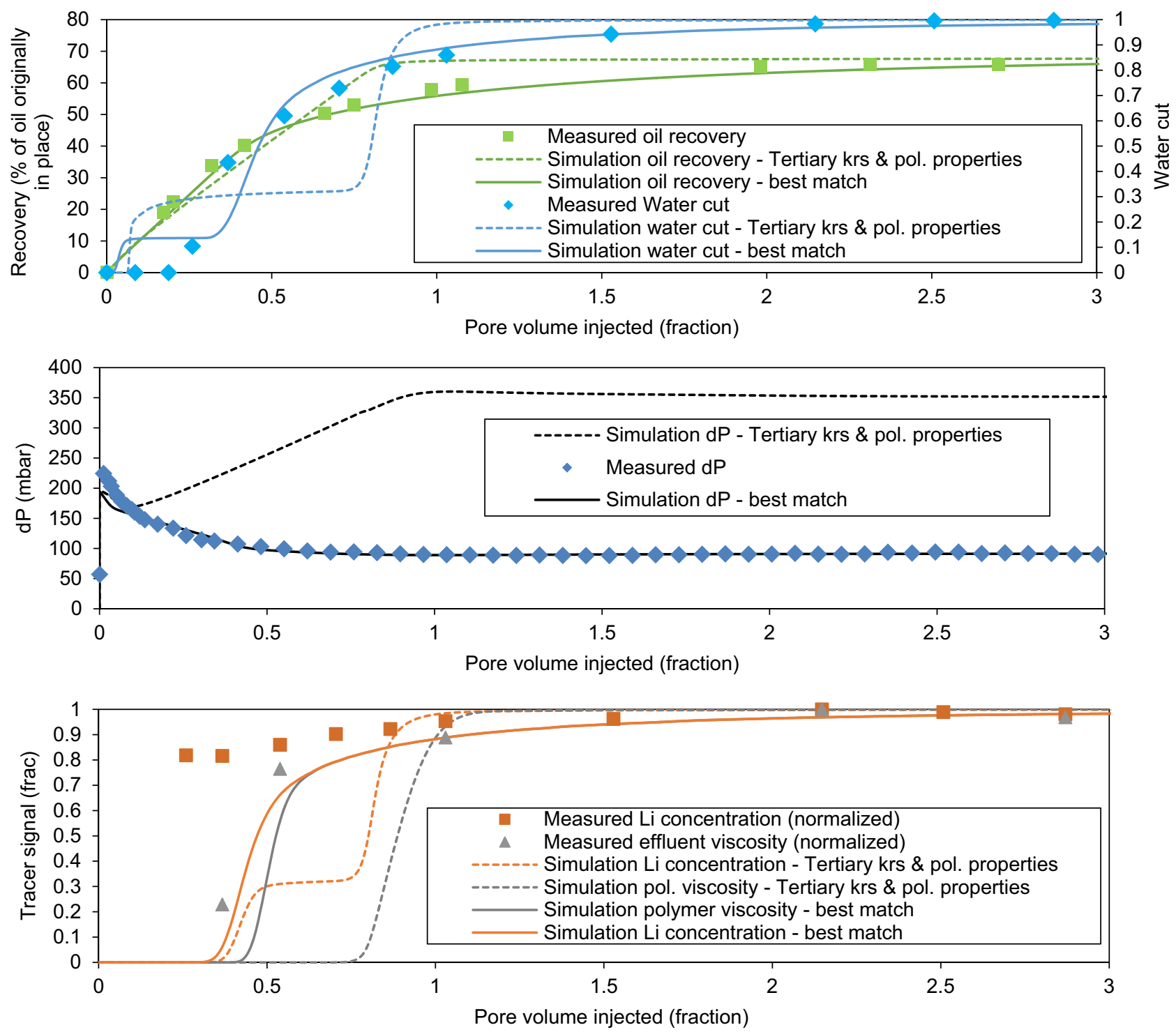

Fig. 13. Experiment S8 history matching results and comparison with the simulation obtained by scaling of T7g water flood $k_{\mathrm{rs}}$ and use of measured and history matched RRF.

$$
\begin{aligned}
& k_{\mathrm{rw}}=K_{r w 2}\left(S_{\mathrm{w} 2}^{*}\right) \frac{K_{r w}\left(S_{\mathrm{wh}}\right)}{K_{r w}\left(1-S_{\mathrm{or}}\right)}, \\
& S_{\mathrm{w} 2}^{*}=S_{\mathrm{wrm}}+\frac{S_{\mathrm{w}}-S_{\mathrm{wrh}}}{1-S_{\mathrm{or}}-S_{\mathrm{wrh}}}\left(1-S_{\mathrm{or}}-S_{\mathrm{wrm}}\right),
\end{aligned}
$$

where $S_{\text {wrh }}$ is an intermediate residual saturation associated with this scanning curve. It can be calculated by Land's formula (Land, 1968):

$$
\begin{aligned}
S_{\mathrm{wrh}} & =S_{\mathrm{wr}}+\frac{S_{\mathrm{wh}}-S_{\mathrm{wr}}}{1+C\left(S_{\mathrm{wh}}-S_{\mathrm{wr}}\right)}, \\
C & =\frac{1}{S_{\mathrm{wrm}}-S_{\mathrm{wr}}}-\frac{1}{1-S_{\mathrm{or}}-S_{\mathrm{wr}}} .
\end{aligned}
$$

$K_{\text {rw2 }}$ was given by a Corey-type function and we applied Land's formula. Hence hysteresis modelling only requires two parameters, namely the Corey exponent for $K_{\mathrm{rw} 2}$ and the maximum residual water saturation $\left(S_{\mathrm{wrm}}\right)$.

\subsubsection{Secondary polymer flood history match}

To compare secondary and tertiary polymer flood, the model used for experiment S8 is 1D, with same grid size as the tertiary experiments. Permeability, porosity, and initial saturation are uniformly distributed based on Table 1.

Figure 13 illustrates that tertiary $k_{\mathrm{rs}}$ scaled on the three end points $\left(S_{\mathrm{wi}}, S_{\mathrm{or}}\right.$, and $\left.k_{\mathrm{rw}}\left(S_{\mathrm{or}}\right)\right)$, together with the polymer properties from tertiary history matching, do not enable to capture the pressure gradient nor the effluents breakthrough. With these assumptions, pressure is overestimated by 250 mbar; water breakthrough is predicted before 0.1 PVI whereas it is seen at 0.23 PVI during the experiment; and oil recovery is predicted after 1 PVI whereas 
approximately $7 \%$ of oil in place is recovered from 1 PVI to 3 PVI. Tracers breakthrough (polymer and Lithium) are predicted significantly too late, consistently with aqueous front simulated being much more stable than observations.

A better match has been obtained with different polymer parameters: in-situ viscosity is assumed to be identical to the one during tertiary displacement, but RRF and adsorption are decreased as shown in Table 6. Additionally, in order to match the polymer breakthrough, IPV is increased to 0.4 , the limit of the range of simulator numerical stability. This set of value is one of the possible combinations, as adsorption and IPV influence independently and adversely the polymer velocity (Green and Willhite, 1998). The low value of RRF necessary to match the pressure differential depends on the estimated value for $k_{\mathrm{rw}}\left(S_{\mathrm{or}}\right)$, here 0.08 , which is close to the values estimated for the other tertiary experiments $(0.115-0.155)$, as mentioned in previous work (de Loubens et al., 2018; Fabbri et al., 2015). End point relative permeabilities estimations should be considered with care as they either depend on polymer in-situ viscosity or require many pore volume of water to ensure no polymer is left in the core (Seright, 2017).

Note that $\mathrm{RRF}=4$ used for history matching of tertiary experiments is based on in-situ rheology experiments in water saturated core (Fabbri et al., 2015) and is consistent with experimental values reported in the literature for similar permeabilities, although it may be higher than values expected in the field (Seright, 2017). RRF value close to unity for the secondary flood is consistent with the understanding that cores at residual oil saturation exhibit different adsorption (Broseta et al., 1995), rheological behavior (Skauge et al., 2018) and is in line with other $\mathrm{RRF}$ measurements reported in the literature (Al-Shakry et al., 2018; Masalmeh et al., 2019).

However, Li tracer and polymer breakthrough are still predicted approximately 0.2 PVI later than what was observed experimentally. The simulations also underestimate the concentration of tracer found in the produced water at early time, because the dilution of tracer in connate water is overestimated. In the simulation, $S_{\mathrm{wi}}$ water is displaced ahead of the injected solution and breaks through rapidly: the tracer and polymer concentration increase once connate water has been produced. In reality the water phase at $S_{\mathrm{wi}}$ after maturation may be discontinuous and the irregular front of aqueous phase observed in Figure 10 contacts only a fraction of the connate water. Similar observation was also done by Brown on 2-3 Darcy unconsolidated sand with $140 \mathrm{cP}$ oil and $\mathrm{S}_{\mathrm{wi}} \approx 0.1$ (Brown, 1957).

\subsubsection{Use of water flood, secondary, and tertiary polymer flood relative permeabilities for field application}

Figure 14 compares the relative permeability ratio $k_{\mathrm{rw}} / k_{\mathrm{ro}}$ on the saturation ranges $\left[S_{\text {wfmin }} S_{\text {wfmax }}\right]$ investigated during water flood, tertiary, and secondary polymer flooding. $S_{\text {wmin }}$ is the average water saturation in the core at the water breakthrough and $S_{\text {wfmax }}$ is the averaged water saturation in the core at the end of the flood. By construction, water flood and tertiary polymer flood saturation domains are

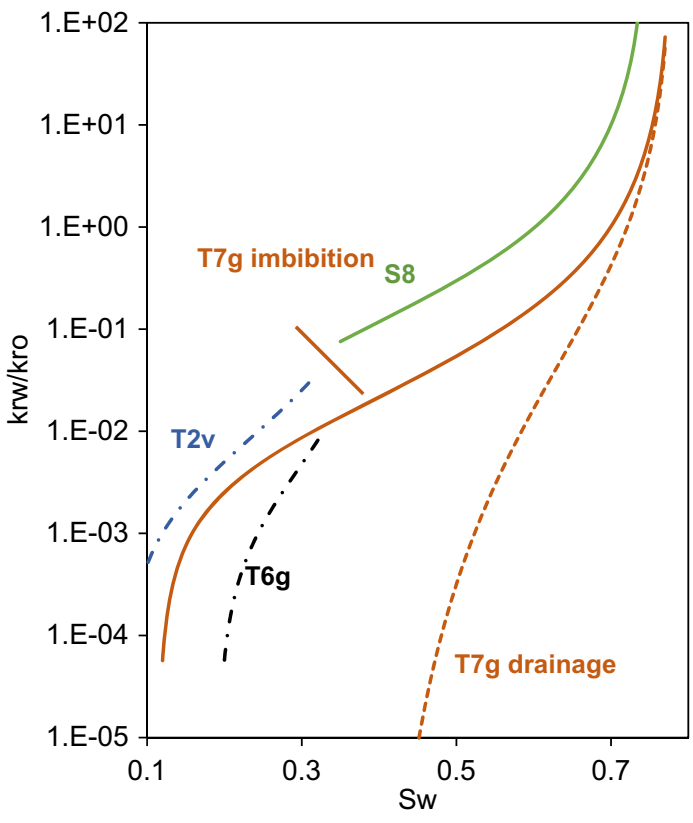

Fig. 14. Comparison of water flood, secondary and tertiary polymer flood relative permeability ratios $\left(k_{\mathrm{rw}} / k_{\mathrm{ro}}\right)$.

distinct. $\mathrm{T} 2 \mathrm{v}$ and $\mathrm{T} 6 \mathrm{~g} k_{\mathrm{rw}} / k_{\mathrm{ro}}$ are represented as upper and lower boundaries of the domain investigated during the water flood. $\mathrm{T} 7 \mathrm{~g}$ imbibition and drainage $k_{\mathrm{rw}} / k_{\mathrm{ro}}$ are plotted on the whole range of saturation, as used for tertiary polymer flooding simulation, even though it was not history matched on the whole interval (Fabbri et al., 2015). Comparison with $\mathrm{S} 8 k_{\mathrm{rs}}$ ratio further highlights that polymer solution is more mobile during secondary than during tertiary floods.

For polymer field application, relative permeabilities derived from secondary and tertiary experiments, presented in Figure 14, could be used as guides for sensitivity analysis. They should be used with great care, given the observations made in this paper or in previous works:

1. Secondary polymer flood is at the limit of the stability domain, as shown on Figures 10, 11, and 13. The tracer's breakthrough history match challenges also evidence that simulators fail to predict correctly the mixing with connate water in such viscous oil.

2. Tertiary polymer flood is more stable than secondary and could be correctly predicted by Darcy-type equation with hysteretic relative permeability, necessary to predict the oil bank velocity (Fabbri et al., 2015). However, accurate viscous fingering pattern could not be predicted at core scale by classic Darcy-type simulators (de Loubens et al., 2018) and simulations have been initialized with saturation maps at the end of the water flood.

3. Relative permeabilities obtained in homogeneous porous media may need upscaling, as industry applications require field scale simulations to assess polymer floods stakes in heterogeneous geology or test different development patterns. Building on correlations 
Table 2. Summary of second set of experiments.

\begin{tabular}{|c|c|c|c|c|c|c|c|c|c|}
\hline \multirow[t]{2}{*}{ Exp } & \multirow[t]{2}{*}{ Geometry } & \multirow[t]{2}{*}{ Size $(\mathrm{cm})$} & \multirow[t]{2}{*}{$\begin{array}{l}\text { Porosity } \\
\text { (fraction) }\end{array}$} & \multicolumn{2}{|c|}{$\begin{array}{c}\text { Permeability } \\
\text { (Darcy) }\end{array}$} & \multirow{2}{*}{$\begin{array}{c}\text { Initial } \\
\text { water } \\
\text { saturation } \\
\text { (fraction) }\end{array}$} & \multirow{2}{*}{$\begin{array}{c}\text { Oil } \\
\text { viscosity } \\
(\mathrm{cP})\end{array}$} & \multicolumn{2}{|c|}{$\begin{array}{c}\text { Viscosity ratio } \\
\left(\mu_{\mathrm{r}}\right)\end{array}$} \\
\hline & & & & $\begin{array}{c}K_{\mathrm{w}} \\
\left(S_{\mathrm{w}}^{=}=1\right)\end{array}$ & $\begin{array}{c}K_{o}\left(S_{\mathrm{wi}}\right) \\
\text { after aging }\end{array}$ & & & $\begin{array}{l}\text { Water } \\
\text { flood }\end{array}$ & $\begin{array}{c}\text { Polymer } \\
\text { flood } \\
\end{array}$ \\
\hline $\mathrm{T} 2 \mathrm{v}$ & 2D slab & $30 \times 30 \times 2.1$ & 0.22 & 2.8 & 1.2 & 0.07 & 7000 & 7368 & 117 \\
\hline T3b & $2 \mathrm{D}$ slab & $30 \times 30 \times 2.6$ & 0.25 & 2.5 & 2.5 & 0.13 & 2000 & 2105 & 29 \\
\hline $\mathrm{T} 4 \mathrm{~b}$ & $2 \mathrm{D}$ slab & $20 \times 30 \times 2.2$ & 0.22 & 2.7 & 2.5 & 0.09 & 2000 & 2105 & 29 \\
\hline $\mathrm{T} 5 \mathrm{~g}$ & Cubic & $30 \times 30 \times 30$ & 0.24 & $\approx 2.5$ & - & 0.09 & 2000 & 2105 & 29 \\
\hline T6g & $\begin{array}{l}\text { Quarter- } \\
\text { five-spot }\end{array}$ & $30 \times 30 \times 2.2$ & 0.22 & - & - & 0.13 & 2000 & 2105 & 29 \\
\hline $\mathrm{T} 7 \mathrm{~g}$ & $2 \mathrm{D}$ slab & $30 \times 90 \times 2.5$ & 0.22 & 2.5 & 2.2 & 0.11 & 2000 & 2105 & 29 \\
\hline S8 & 2D slab & $15 \times 15 \times 2.1$ & 0.22 & 2.0 & - & 0.10 & 2000 & 2105 & 29 \\
\hline
\end{tabular}

Table 3. Pore velocity estimation during polymer injection.

\begin{tabular}{lc}
\hline Experiment & $u(\mathrm{~cm} /$ day $)$ \\
\hline S0 & 3.4 \\
T1 & 3.5 \\
T2v & 4.9 \\
T3b & 3.8 \\
T4b & 4.9 \\
T6g & - \\
T7g & 4.4 \\
S8 & 5.0
\end{tabular}

Table 4. Ionic composition of the brine used for set 1 and set 2 .

Component Water content set 1 Water content set 2

\begin{tabular}{lcc} 
& $(\mathrm{mg} / \mathrm{L})$ & $(\mathrm{mg} / \mathrm{L})$ \\
\hline $\mathrm{Na}^{+}$ & 1581 & 2634 \\
$\mathrm{Cl}^{-}$ & - & 3640 \\
$\mathrm{HCO}_{3}^{-}$ & 2178 & 727 \\
$\mathrm{I}^{-}$ & 4233 & - \\
TDS & 8000 & 7000 \\
\hline
\end{tabular}

Table 5. Summary of experiments results at the end of water and polymer floods.

\begin{tabular}{|c|c|c|c|c|c|c|c|c|}
\hline \multirow[t]{2}{*}{ Set } & \multirow[t]{2}{*}{ Experiment } & \multirow{2}{*}{$\begin{array}{c}\text { Water } \\
\text { breakthrough } \\
\text { time } \\
(\mathrm{PVI})\end{array}$} & \multirow{2}{*}{$\begin{array}{c}\begin{array}{c}\text { Recovery after } \\
1 \mathrm{PV} \text { water flood }\end{array} \\
\mathrm{RF}(\%)\end{array}$} & \multicolumn{2}{|c|}{$\begin{array}{c}\text { Recovery after } \\
\text { water flood }\end{array}$} & \multirow{2}{*}{$\begin{array}{c}\begin{array}{c}\text { Recovery after } \\
1 \mathrm{PV} \text { polymer flood }\end{array} \\
\mathrm{RF}(\%)\end{array}$} & \multicolumn{2}{|c|}{$\begin{array}{l}\text { Recovery after } \\
\text { polymer flood }\end{array}$} \\
\hline & & & & $\begin{array}{c}\mathrm{PV} \\
\text { injected }\end{array}$ & $\mathrm{RF}(\%)$ & & $\begin{array}{c}\mathrm{PV} \\
\text { injected }\end{array}$ & $\begin{array}{c}\text { Incremental } \\
\mathrm{RF}(\%)\end{array}$ \\
\hline \multirow[t]{2}{*}{1} & S0 & 0.27 & - & - & - & 55.2 & 1.7 & 59 \\
\hline & $\mathrm{T} 1$ & $<0.1$ & 21.2 & 1.8 & 28 & 45.2 & 2 & 47 \\
\hline \multirow[t]{7}{*}{2} & $\mathrm{~T} 2 \mathrm{v}$ & 0.028 & 15.5 & 5.1 & 26 & 22.7 & 3 & 37 \\
\hline & $\mathrm{T} 3 \mathrm{~b}$ & 0.044 & 22.0 & 2.3 & 29 & 36.6 & 3.2 & 38 \\
\hline & $\mathrm{T} 4 \mathrm{~b}$ & 0.044 & 30.4 & 2.5 & 39 & 28.6 & 3 & 34 \\
\hline & $\mathrm{T} 5 \mathrm{~g}$ & 0.038 & 26.3 & 4.5 & 37 & - & Plugging & Plugging \\
\hline & T6g & 0.043 & 18.9 & 2.3 & 23 & 40.7 & 2 & 44 \\
\hline & $\mathrm{T} 7 \mathrm{~g}$ & 0.042 & 25.6 & 2.7 & 37 & 36.5 & 1.2 & 38 \\
\hline & $\mathrm{S} 8$ & 0.23 & - & - & - & 58.2 & 3 & 66 \\
\hline
\end{tabular}

obtained from extensive experimental work (Doorwar and Mohanty, 2017) Luo et al. (2017), proposed an upscaling approach to account for viscous fingering at core scale and channeling at the intermediate scale. This model could be calibrated using lab experiments at core scale and extended at intermediate scale using geostatistical realizations on fine grid. This approach also enabled to estimate the impact of viscous fingering on field scale production profiles (Luo et al., 2016), without hysteresis. For less viscous oil, another 
Table 6. Comparison of polymer properties used as input for secondary and tertiary experiments.

\begin{tabular}{lcc}
\hline & $\begin{array}{c}\text { Tertiary } \\
\text { experiments }\end{array}$ & $\begin{array}{c}\text { Secondary } \\
\text { experiment }\end{array}$ \\
\hline Viscosity $(\mathrm{cP})$ & 70 & 70 \\
Adsorption $(\mu \mathrm{g} / \mathrm{g}$ of rock) & 50 & 10 \\
IPV (dimensionless, in & 0.05 & 0.4 \\
porosity unit) & & \\
$\mathrm{RRF}$ (dimensionless) & 4 & 1 \\
$k_{\mathrm{rw}}\left(S_{\text {or }}\right)$ (dimensionless) & $\sim 0.1$ & 0.08 \\
\hline
\end{tabular}

solution is to adjust relative permeabilities by history matching results with different grid size, heterogeneity, and water flood maturity, to ensure the recoveries and effluent breakthrough are adequately predicted from lab scale simulations to field scale (Bourgeois et al., 2019). Alternative simulation approaches for viscous oils aims at capturing unstable flows with less computationally expensive numerical schemes, like unstructured mesh simulations showing viscous fingers development for $300 \mathrm{cP}$ oil (Adam et al., 2017).

Practically, experimental observations gathered in this work also highlight the importance of capturing water distribution from saturation and production logs before polymer injection start-up, to obtain more reliable polymer injection forecast.

\section{Conclusion}

The new experimental results presented here for experiments T5g and S8 are the last of two sets of experiments aiming to decrease simulation uncertainties for secondary and tertiary polymer floods in very viscous oil. The two sets were performed with different porous media and temperature conditions but led to consistent results. The effect of injection rail, geometry, viscosity, and injection sequence on polymer properties and relative permeabilities could be investigated.

1. The experimental results presented enable to quantify the variance of water flood recoveries at adverse mobility ratio, prior to polymer injection. Change in viscosity of the oil from $2000 \mathrm{cP}$ to $7000 \mathrm{cP}$, or different injection geometry - quarter of five spot instead of linear flow - or non-uniform distribution of the flow across the injection rail can lead to recoveries ranging from $15 \%$ to $30 \%$ after one pore volume of water injected.

2. The secondary polymer flood performed in consolidated sandstone is consistent with the observations made during secondary experiment in unconsolidated sandstone and confirm that such displacement is less stable than the tertiary one. In particular, the polymer solution breakthrough time is at approximately 0.3 PVI in secondary mode, whereas it is after
0.5 PVI for the tertiary experiments. Consistently recoveries after $1 \mathrm{PV}$ of polymer injected is lower than $60 \%$ for secondary, whereas it is higher than $65 \%$ for tertiary mode after water flooding and 1 PVI of polymer.

3. The hysteresis phenomenon identified during oil banking in previous publications does not allow to explain completely the difference between secondary and tertiary polymer floods, especially in terms of pressure evolution. Two mechanisms may be at play: hysteresis during the mobilization of oil bank in tertiary mode and lower resistance factor in the presence of high oil saturation. $\mathrm{RRF}=4$ was used for history match of the tertiary experiments, in line rheology experiments carried in fully saturated Bentheimer cores, whereas $\mathrm{RRF}=1$ was required for the history matching of secondary experiment S8, assuming constant in-situ viscosity.

4. Impact for field implementation: in this article, secondary and tertiary relative permeabilities differ and should be chosen depending on the initial water flooding status of the field considered. Water and polymer flood performance prediction may need upscaling of laboratory measurement and additional data acquisition to understand water distribution before polymer injection start-up. The authors suggest keeping a low RRF, close to unity, if the polymer displacement is expected to be mostly in secondary mode, which is expected to be the case when the water breakthrough is very rapid. However, when highly permeable zones are present, the importance of crossflow from the low to high permeable zone (Craig, 1971; Sorbie and Seright, 1992; Sorbie and Skauge, 2019) will require a proper characterization of the polymer adsorption and resistance factors in water flooded porous media.

Acknowledgments. The authors would like to thank Total S.A. for the authorization to publish this paper and the CIPR for fruitful exchanges.

\section{References}

Adam A., Percival J., Salinas P., de Loubens R., Pain C., Muggeridge A., Jackson M. (2017) Dynamic mesh adaptivity for immiscible viscous fingering, in: SPE Reservoir Simulation Conference, Society of Petroleum Engineers, Montgomery, TX, USA.

Al-Shakry B., Shiran B.S., Skauge T., Skauge A. (2018) Enhanced oil recovery by polymer flooding: Optimizing polymer injectivity, in: SPE Kingdom of Saudi Arabia Annual Technical Symposium and Exhibition, SPE, Dammam, Saudi Arabia.

Artus V., Noetinger B., Ricard L. (2004) Dynamics of the wateroil fron for two-phase, immiscible flow in heterogeneous porous media, Transp. Porous Media 56, 3, 283-303.

Asghari K., Nakutnyy P. (2008) Experimental results of polymer flooding of heavy oil reservoirs, in: Petroleum Society's 59th Annual technical meeting, Society of Petroleum Engineer, Calgary, AB, Canada. 
Blunt M.J. (2001) Flow in porous media - pore-network models and multiphase flow, Curr. Opin. Colloid Interface Sci. 6, 197-207.

Bondino I., Nguyen R., Hamon G., Ormehaug P., Skauge A., Jouenne S. (2011) Tertiary polymer flooding in extra-heavy oil: An investigation using $1 \mathrm{D}$ and $2 \mathrm{D}$ experiments, core scale simulation and pore scale network models, in: Paper SCA2011-1063 presented at the International Symposium of the Society of Core Analyst held in Austin, TX, 2011.

Bouquet S., Douarche F., Roggero F., Leray S. (2019) Characterization of viscous fingering and channeling for the assessment of polymer-based heavy oil displacements, Transp. Porous Media 131, 873-906.

Bourgeois M., Hild J.-C., Bursaux R. (2019) Impact of upscaling on numerical estimation of polymer increments, in: $S P E$ EUROPEC 2019 81st EAGE Annual Conference \& Exhibition, Society of Petroleum Engineers, London, UK.

Broseta D., Medjahed F., Lecourtier J., Robin M. (1995) Polymer adsorption/retention in porous media: Effects of core wettability and residual oil, SPE Adv. Technol. Ser. 3, 1, 104-112.

Brown W. (1957) The mobility of connate water during water flood, Petrol. Trans. AIME 210, 190-195.

Buchgraber M., Clemens T., Castanier L.M., Kovscek A.R. (2011) A microvisual study of the displacement of viscous oil by polymer solutions, SPE Res. Eval. Eng. 14, 269-280.

Buckley S., Leverett M. (1942) Mechanism of fluid displacements in sands, Trans. AIME 146, 1, 107-116.

Chauveteau G. (1981) Molecular interpretation of several different properties of flow of coiled polymer solutions through porous media in oil recovery, in: SPE Annual Technical Conference and Exhibition, Society of Petroleum Engineers, San Antonio, TX, USA.

Chen G., Li Y., Wang J., Ma M., Lu K., Jin G., Sun H. (2008) An applied chemical flooding simulator and its application in daqing oilfield, in: SPE Symposium on Improved Oil Recovery, Society of Petroleum Engineers, Tulsa, OK, USA.

Chen G., Shao Z., Zhang X., Ma M., Lu K., Wei C. (2011) History matching method for high concentration viscoelasticity polymer flood pilot in daqing oilfield, in: SPE Enhanced Oil Recovery Conference, Society of Petroleum Engineers, Kuala Lumpur, Malaysia.

Craig F.F. (1971) The reservoir engineering aspects of waterflooding, Monograph Series, Society of Petroleum Engineers, Richardson, TX.

D'Angelo M.V., Fontana E., Chertcoff R., Rosen M. (2003) Retention phenomena in non-Newtonian fluids flow, Phys. A Stat. Mech. Appl. 327, 44-48.

de Loubens R., Vaillant G., Regaieg J., Yang J., Moncorge A., Fabbri C., Darche G. (2018) Numerical modeling of unstable waterfloods and tertiary polymer floods into highly viscous oil, SPE J. 23, 1909-1928.

Delamaide E. (2016) Comparison of primary, secondary and tertiary polymer flood in heavy oil - field results, in: $S P E$ Trinidadand Tobago Section Energy Resources Conference, Society of Petroleum Engineers, Port of Spain.

Delamaide E., Corlay P. (1994) Daqing oil field: The success of two pilots initiates first extension of polymer injection in a giant oil field, in: SPE/DOE Ninth Symposium on Improved Oil Recovery, Society of Petroleum Enigneers, Tulsa, Ok.

Delamaide E., Zaitoun A., Renard G., Tabary R. (2013) Pelican lake field: First successful application of polymer flooding in a heavy oil reservoir, in: Paper SPE 165234, Presented at the SPE Enhance Oil Recovery Conference, Kuala Lumpur, Malaysia, 2013.

Delshad M., Pope G.A., Sepehrnoori K. (2000) Volume II: Technical documentation for UTCHEM 2013_8: A threedimensional chemical flood simulator, Reservoir Engineering Research Program, Center for Petroleum and Geosystems Engineering, University of Texas, Austin, TX.

Doorwar S., Mohanty K.K. (2011) Viscous fingering during nonthermal heavy oil recovery, in: SPE Annual Technical Conference and Exhibition, 30 October-2 November, Denver, CO, USA, SPE-146841.

Doorwar S., Mohanty K. (2014) Polymer flood of viscous oil in complex carbonates, in: SPE Improved Oil Recovery Symposium, Society of Petroleum Engineers, Tulsa, OK, USA.

Doorwar S., Mohanty K. (2017) Viscous-fingering function for unstable immiscible flows, SPE J. 22, 19-31.

Fabbri C., Cottin C., Jimenez J., Nguyen M., Hourcq S., Bourgeois M., Hamon G. (2014) Secondary and tertiary polymer flooding in extra-heavy oil: Reservoir conditions measurements - performance comparison, in: Paper IPTC17703, presented at the International Petroleum Technology Conference, Society of Petroleum Engineers, Doha, Qatar.

Fabbri C., de Loubens R., Skauge A., Ormehaug P., Vik B., Bourgeois M., Morel D., Hamon G. (2015) Comparison of history-matched water flood, tertiary polymer flood relative permeabilities and evidence of hysteresis during tertiary polymer flood in very viscous oils, in: SPE Enhanced Oil Recovery Conference, Society of Petroleum Engineers, Kuala Lumpur, Malaysia.

Fabbri C., Romero C., Aubertin F., Nguyen M., Hourcq S., Hamon G. (2013) Secondary polymer flooding in extra-heavy oil: Gaining information on polymer-oil relative permeabilities, in: Paper SPE 165237, paper prepared for the SPE Enhanced Oil Recovery Conference, Kuala Lumpur.

Fransham P.B., Jelen J. (1987) Displacement of heavy oil visualized by CAT Scan, J. Can. Pet. Tech. 26, 42-47.

Gao C. (2011) Advances of polymer flood in heavy oil recovery, in: Paper SPE 150384, Prepared for the SPE Heavy Oil Conference and Exhibition, Kuwait City, Kuwait.

Gogarty W. (1967) Mobility control with polymer solutions, Soc. Pet. Eng. J. 7, 162-173.

Grattoni C., Luckham P., Jing X., Norman L., Zimmerman R. (2004) Polymer as relative permeability modifiers: Adsorption and the dynamic formation of thick polyacrylamide layers, $J$. Pet. Sci. Eng. 45, 233-245.

Green D., Willhite P. (1998) Enhanced oil recovery, Society of Petroleum Engineers, Richardson, Texas, USA.

Hagoort J. (1974) Displacement stability of water drives in waterwet connate-water-bearing reservoirs, SPE J. 14, 1, 36-74.

Hassaizadeh S., Gray W. (1990) Mechanics and thermodynamics of multiphase flow in porous media including interphase boundaries, Adv. Water Resour. 13, 169-186.

Huh C., Pope G. (2008) Residual oil saturation from polymer flood: Laborator measurements and theoretical interpretation, in: SPE Symposium on Improved Oil Recovery, Society of Petroleum Engineers, Tulsa, OK, USA.

Jadhunandan P., Morrow N. (1995) Effect of wettability on waterflood recovery for crude-oil/brine/rock systems, SPE Reserv. Eng. 10, 1, 40-46.

Juarez-Morejon J.L., Bertin H., Omari A., Hamon G., Cottin C., Morel D., Romero C., Bourdarot G. (2018) A new approach to 
polymer flooding: Impact of the early polymer injection and wettability on final oil recovery, in: SPE Europec at 80th EAGE Conference and Exhibition, SPE, Copenhagen.

Kalaydjian F. (1990) Origin and quantification of coupling between relative permeabilities for two-phas flows in porous media, Transp. Porous Media 5, 215-229.

Land C. (1968) Calculation of imbibition relative permeability for two- and three-phase flow from rock properties, Soc. Pet. Eng. J. 8, 149-156.

Lenormand R., Touboul E., Zarcone C. (1988) Numerical models and experiments on immiscible displacements in porous media, J. Fluid Mech. 189, 165-167.

Lenormand R., Zarcone C., Sarr A. (1983) Mechanisms of the displacement of one fluid by another in a network of capillary ducts, J. Fluids Mech. 135, 337-353.

Levitt D., Jouenne S., Bondino I., Gingras J., Bourrel M. (2011) The interpretation of polymer coreflood results for heavy oil, in: SPE Heavy Oil Conference and Exhibition, 12-14 December, Kuwait City, Kuwait. SPE150566.

Luo H., Delshad M., Pope G., Mohanty K.K. (2017) Interactions between viscous fingering and channeling for unstable water/ polymer floods in heavy oil reservoirs, in: SPE Reservoir Simulation Conference, SPE, Montgomery, TX, USA.

Luo H., Mohanty K.K., Delshad M., Pope G.A. (2016) Modeling and upscaling unstable water and polymer floods: Dynamic characterization of the effective finger zone, in: SPE Improved Oil Recovery Conference, SPE, Tulsa, OK, USA.

Masalmeh S., AlSumaiti A., Gaillard N., Daguerre F., Skauge T., Skauge A. (2019) Extending polymer flooding towards hightemperature and high-salinity reservoirs, in: Abu Dhabi International Petreoleum Exhibition $\&$ Conference, SPE, Abu Dhabi, UAE.

Muskat M. (1937) The flow of homogeneous fluids through porous media, McGraw - Hill Book Company, New York, NY.

Niessner J., Berge S., Hassanizadeh S. (2011) Comparison of two-phase Darcy's law with a thermodynamically consistent approach, Transp. Porous Media 88, 133-148.

Ning S., Barnes J., Edwards R., Dunford K., Easthan K., Dandekar A., Zhang Y., Cercone D., Ciferno J. (2019) First ever polymer flood field pilot to enhance the recovery of heavy oils on Alaska's north slope - polymer injection perfomance, in: Unconventional Resources Technology Conference, Society of Petroleum Engineers, Denver, CO.

Oren P.-E., Bakke S., Arntzen O. (1998) Extending predictive capabilities to network models, SPE J. 3, 324-336.

Pancharoen M.T., Kovscek A. (2010) Inaccessible pore volume of associative polymer floods, in: SPE Improved Oil Recovery Symposium, Society of Petrolem Engineers, Tulsa, OK, USA.

Pandey A., Kumar M., Beliveau D., Corbishley D. (2008) Chemical flood simulation of laboratory corefloods for the Mangala field: Generating parameters for field scale simulation, in: SPE Symposium on Improved Oil Recevery, Society of Petroleum Engineers, Tulsa, OK, USA.

Patacchini L., de Loubens R., Moncorgé A., Trouillaud A. (2014) Four-fluid-phase, fully implicit simulation of surfactant flooding, SPE Res. Eval. 17, 271-285.

Riaz A., Tang G.Q., Tchelepi H., Kovscek A.R. (2007) Forced imbibitions in natural porous media: Comparison between experiments and continuum models, Phys. Rev. E 75, 036305.

Riaz A., Tchelepi H.A. (2004) Linear stability analysis of immiscible two-phase flow in porous media with capillary dispersion and density variation, Phys. Fluids 16, 4727-4737.
Riaz A., Tchelepi H.A. (2006) Numerical simulation of immiscible two-phase flow in porous media, Phys. Fluids 18, 1, 014104.

Saffman P., Taylor F. (1958) The penetration of a fluid into a porous medium or Hele-Shaw cell containing a more viscous liquid, Proc. Royal Soc. 245, 312-329.

Seright R.S. (2017) How much polymer should be injected during a polymer flood? Review of previous and current practices, SPE J. 22, 1, 1-18.

Seright R., Wang D., Lerner N., Nguyen A., Sabid J., Tochor R. (2018) Can 25-cp polymer solution efficiently displace 1,600cp oil during polymer flooding? SPE J. 23, 2260-2278.

Skauge A., Horgen T., Noremark B., Vik B. (2011) Experimental studies of unstable displacement in carbonate and sandstone material, in: Paper $n^{\circ} 9880$ presented at the EAGE IOR Symposium, Cambridge, UK.

Skauge A., Ormehaug P., Gurholt T., Vik B., Bondino I., Hamon G. (2012) 2-D visualisation of unstable waterflood and polymer flood for displacement of heavy oil, in: Paper SPE 154292, Presented at the 18th SPE Oil Recovery Symposium Held in Tulsa, OK, USA, 2012.

Skauge T., Skauge A., Salmo I.C., Ormehaug P.A., Al-Azri N., Wassing M., Glasbergen G., Van Wunnik J.N., Masalmeh S.K. (2016) Radial and linear polymer flow - influence on injectivity, in: SPE Improved Oil Recovery Conference, Society of Petroleum Engineers, Tulsa, OK, USA.

Skauge A., Sorbie K., Ormehaug P., Skauge T. (2009) Experimental and numerical modeling studies of viscous unstable displacement, in: Paper A 28, Presented at the 15th European Symposium on Improved Oil Recovery - Paris, France, April 27-29, 2012.

Skauge T., Vik B., Ormehaug P., Jatten B., Kippe V., Skjevrak I., Standnes D., Uleberg K., Skauge A. (2014) Polymer flood at adverse mobility ratio in $2 \mathrm{D}$ flow by X-ray visualization, in: Paper SPE 169740, Presented at the SPE EOR Conference at Oil and Gas West Asia held in Muscat, Oman.

Skauge A., Zamani N., Jacobsen J., Shiran B., Al-Shakry B., Skauge T. (2018) Polymer flow in porous media: Relevance to enhanced oil recovery, Colloids Interf. 2, 2-27.

Sorbie K.S., Seright R.S. (1992) Gel placement in heterogeneous systems with crossflow, in: SPE/DOE Enhanced Oil Recovery Symposium, Society of Petroleum Engineers, Tulsa, OK, USA.

Sorbie K., Skauge A. (2019) Mobilization of by-passed oil by viscous crossflow in EOR processes, in: IOR 2019 - 20th European Symposium on Improved Oil Recovery, EAGE, Pau. van der Post N., Masalmeh S.K., Coenen J.G., van der Gijp K.H., Maas J.G. (2000) Relative permeability, hysteresis and I-Sw measurements on a carbonate prospect, in: 14th International Symposium of the Society of Core Analyst, Abu Dhabi.

Vik B., Kedir A., Kippe V., Sandengen K., Skauge T., Solbakken Z.D. (2018) Viscous oil revovery by polymer injection; impact of in-situ polymer rheology on water front stabilization, in: SPE Europec featured at 20th EAGE Conference and Exhibition, Society of Petroleum Engineers, Copenhagem, Denmark.

Wang J., Dong M. (2009) Optimum effective viscosity of polymer solution for improving heavy oil recovery, J. Pet Sci. Eng. 67, 155-158.

Wassmuth F., Arnold W., Green K., Cameron N. (2009) Polymer flood application to improve heavy oil recovery at East Bodo, JCPT 48, 2, 55-61.

Xu B., Kamath J., Yorsos Y., Lee S. (1999) Use of pore-network models to simulate laboratory corefloods in a heterogeneous carbonate sample, SPE J. 4, 179-186. 